\title{
Quantitative evaluation of seven optical sensors for cloud microphysical measurements at the Puy-de-Dôme Observatory, France
}

\author{
G. Guyot ${ }^{1}$, C. Gourbeyre ${ }^{1}$, G. Febvre ${ }^{1}$, V. Shcherbakov ${ }^{1,4}$, F. Burnet ${ }^{2}$, J.-C. Dupont ${ }^{3}$, K. Sellegri ${ }^{1}$, and O. Jourdan ${ }^{1}$ \\ ${ }^{1}$ Laboratoire de Météorologie Physique, Université Blaise Pascal, Clermont-Ferrand, France \\ ${ }^{2}$ CNRM/GAME - Météo-France/CNRS, 42 avenue Gaspard Coriolis, 31057 Toulouse, France \\ ${ }^{3}$ Institut Pierre-Simon Laplace, Université Versailles Saint Quentin, 78280 Guyancourt, France \\ ${ }^{4}$ Laboratoire de Météorologie Physique, Institut Universitaire de Technologie d'Allier, Montluçon, France
}

Correspondence to: O. Jourdan (o.jourdan@opgc.univ-bpclermont.fr)

Received: 18 March 2015 - Published in Atmos. Meas. Tech. Discuss.: 3 June 2015

Revised: 10 September 2015 - Accepted: 21 September 2015 - Published: 15 October 2015

Abstract. Clouds have an important role in Earth's radiative budget. Since the late 1970s, considerable instrumental developments have been made in order to quantify cloud microphysical and optical properties, for both airborne and groundbased applications. Intercomparison studies have been carried out in the past to assess the reliability of cloud microphysical properties inferred from various measurement techniques. However, observational uncertainties still exist, especially for droplet size distribution measurements and need to be reduced.

In this work, we discuss results from an intercomparison campaign, performed at the Puy de Dôme in May 2013. During this campaign, a unique set of cloud instruments was operating simultaneously in ambient air conditions and in a wind tunnel. A Particle Volume Monitor (PVM-100), a Forward Scattering Spectrometer Probe (FSSP), a Fog Monitor (FM-100), and a Present Weather Detector (PWD) were sampling on the roof of the station. Within a wind tunnel located underneath the roof, two Cloud Droplet Probes (CDPs) and a modified FSSP (SPP-100) were operating. The main objectives of this paper are (1) to study the effects of wind direction and speed on ground-based cloud observations, (2) to quantify the cloud parameters discrepancies observed by the different instruments, and (3) to develop methods to improve the quantification of the measurements.

The results revealed that all instruments showed a good agreement in their sizing abilities, both in terms of amplitude and variability. However, some of them, especially the
FM-100, the FSSP and the SPP, displayed large discrepancies in their capability to assess the magnitude of the total number concentration of the cloud droplets. As a result, the total liquid water content can differ by up to a factor of 5 between the probes. The use of a standardization procedure, based on data of integrating probes (PVM-100 or visibilimeter) and extinction coefficient comparison substantially enhanced the instrumental agreement. During this experiment, the total concentration agreed in variations with the visibilimeter, except for the FSSP, so a corrective factor can be applied and it ranges from 0.44 to 2.2. This intercomparison study highlights the necessity to have an instrument which provides a bulk measurement of cloud microphysical or optical properties during cloud ground-based campaigns. Moreover, the FM and FSSP orientation was modified with an angle ranging from 30 to $90^{\circ}$ angle with wind speeds from 3 to $7 \mathrm{~m} \mathrm{~s}^{-1}$. The results show that the induced number concentration loss is between 29 and $98 \%$ for the FSSP and between 15 and $68 \%$ for the FM-100. In particular, FSSP experiments showed strong discrepancies when the wind speed was lower than $3 \mathrm{~m} \mathrm{~s}^{-1}$ and/or when the angle between the wind direction and the orientation of the instruments is greater than $30^{\circ}$. An inadequate orientation of the FSSP towards the wind direction leads to an underestimation of the measured effective diameter. 


\section{Introduction}

The cloud droplet size distribution is one of the key parameters for a quantitative microphysical description of clouds (Pruppacher and Klett, 1997). It plays an important role in the radiative characteristics of clouds and, for example, is needed to assess the anthropogenic influence on the size and number concentration of cloud droplets (Twomey, 1974, 1977) and on the cloud lifetime (Albrecht, 1989). Moreover, the knowledge of droplet size distribution is crucial for a better understanding of the onset of precipitation (Kenneth and Ochs, 1993) and the aerosol-cloud interaction (McFarquhar et al., 2011). According to Brenguier et al. (2003), aerosol-cloud interaction studies need accurate assessment of the cloud microphysical properties such as liquid water content (LWC), concentration and effective diameter. The representation of liquid stratiform clouds in current climate models is relatively poor, leading to large uncertainties in climate predictions (Randall et al., 2007). Radiative, dynamic and feedback processes involved in liquid clouds still need to be studied (e.g., Petters et al., 2012; Bennartz et al., 2013; Boucher et al., 2013) and thus require accurate measurement instrumentation. In-situ measurements may be directly used for model validations, or to improve and validate remote sensing, radar and lidar retrieval algorithms.

A large number of instruments have been developed since the late 1970s to attempt to obtain precise information on cloud microphysical and optical properties. Two strategies are mainly used to measure in situ properties of clouds. The first one consists of mounting instruments under the wings of an aircraft that flies within the cloud (Gayet et al., 2009; Baumgardner et al., 2011; Brenguier et al., 2013), and the second one consists of instruments operated on a groundbased platform, generally on a mountain site, whose the altitude allows sampling natural clouds (Kamphus et al. 2010; Hoyle et al., 2015).

Generally speaking, cloud in situ probes fall into two categories: single particle counters (SPCs) and ensemble-ofparticles probes (EPP). The later ones measure laser light scattered by an ensemble of droplets passing through the sample volume of the probe (see e.g, Gerber, 1984, 1991; Wendisch et al., 2002). The main measurement principle for the size detection used in most of these devices is based on a conversion of the forward scattering of light into a size bin using the Lorentz-Mie theory (Mie, 1908). However, despite significant technical progress, previous intercomparison studies showed that in situ measurements of cloud particles are still subject to a wide range of biases, uncertainties and limitations (see for instance, Baumgardner, 1983; Gerber et al., 1999; Burnet and Brenguier, 1999, 2002; Lance et al., 2010; Spiegel et al., 2012). The main problems are the assessment of the sampling volume and the impact of the wind speed and direction on ground-based measurements.

Lance et al. (2010) used glass beads to study the calibration accuracy of the Cloud Droplet Probe (CDP). They found that the calibration was consistent with the theoretical instrument response provided by the manufacturer. On the other hand, laboratory experiments with water droplets originated from a piezo-electric drop generator showed a $2 \mu \mathrm{m}$ shift in the size assessment for the diameters between 12 and $23 \mu \mathrm{m}$. The shift was attributed to a misalignment of the optical system. In-flight comparisons of liquid water content (LWC) measurements suggested a bias in the droplet size and/or droplet concentration. This bias was reported to be concentration dependent, due to coincidence events, generally occurring during periods of high concentration, when two or more droplets pass through the CDP laser beam within a very short period of time (Lance et al., 2010). A ground-based cloud experiment performed at the Jungfraujoch, Switzerland, by Spiegel et al. (2012), showed potential biases in the absolute values of the parameters, especially when the Fog Monitor data were compared with parameters provided by other instruments. In addition, the sampling efficiency formula by Hangal and Willeke (1990a, b) were applied with the Fog Monitor characteristics, the results showed that the efficiency decreased quickly for droplets larger than $10 \mu \mathrm{m}$ and angles larger than $30^{\circ}$ in a sub-kinetic regime. However, the efficiency was found to be nearly independent of the sampling angle in a super-kinetic regime (Spiegel et al., 2012). Burnet and Brenguier (2002) also pointed out noticeable differences in fog measurements with airborne instrumentation. A maximum bias of $30 \%$ was found between the LWC measured by the FSSP-100 and the PVM. Based on a ground-based intercomparison study, Gerber et al. (1999) showed that the discrepancies observed between the FSSP and the PVM could be caused by an inertial concentration effect. This effect corresponds to an overestimation of the concentration depending on droplet size in the case of nonisokinetic sampling. Choularton et al. (1986) highlighted an additional wind ramming effect that leads to an overestimation of the concentration caused by the wind speed. Pinnick et al. (1981) also emphasized that Mie curve oscillations can be responsible for sizing errors.

Therefore, although studies comparing cloud properties derived from different methods or instrumentations exist, there is still a need for detailed comparison studies under variable sampling conditions, in order to derive robust standardization and potential corrections of the measurements. Moreover, as Brenguier et al. (2013) concluded, it is still of crucial importance to perform liquid water-cloud instrumental comparison with ground-based experiments.

The research station located on the Puy de Dôme, in central France, is an ideal place for intercomparison studies of cloud microphysical measurements. The station is in clouds approximately $50 \%$ of the time on average (annual mean). The station consists of a platform on the roof, where ground-based instrumentation can be installed, and a wind tunnel facing the dominant western winds used to sample air masses at air speeds up to $55 \mathrm{~m} \mathrm{~s}^{-1}$ in order to reproduce airborne conditions. This paper focuses on the 
cloud instrumentation intercomparison study that was performed in May 2013 within the framework of the ROSEA network (Réseau d'Observatoires pour la Surveillance et l'Exploration de l'Atmosphère, i.e., network of monitoring centers for the study and the supervision of the atmosphere). The first objective of this study is to quantify the discrepancies between some of the cloud microphysical probes available for the scientific community to this date. The peculiarity of this intercomparison lies in the fact that the set of instruments were operating in two different conditions simultaneously. We compared data recorded in ambient conditions and in a wind tunnel. Measurements within a wind tunnel simulate to some extent airborne measurements. The second objective is to derive a method to correct potential biases between these instruments. A third objective is to assess the effect of wind speed and direction on ground-based FSSP and Fog Monitor probes.

Section 2 of this paper presents the measurement site and the instrumentation used during the campaign. Section 3 addresses the comparison of the data recorded with the groundbased and the wind tunnel instruments. A proposed method to correct and standardize these measurements is outlined. Main causes of potential biases and effects of the wind direction and speed are then discussed. Section 4 summarizes the main results and conclusions of this study.

\section{Instrumentation and site}

\subsection{Measurement site}

The cloud microphysics instrumental intercomparison was performed at the Puy-de-Dôme atmospheric measurement station (PUY, $45.46^{\circ} \mathrm{N},{ }^{\circ} \mathrm{E} ; 1465 \mathrm{~m}$ altitude), in central France, as part of the ROSEA project. The station is part of the EMEP (European Monitoring and Evaluation Programme), GAW (Global Atmosphere Watch), and ACTRIS2 (Aerosols, Clouds, and Trace gases Research InfraStructure) networks where atmospheric clouds, aerosols and gases are studied.

The PUY station is located on the top of an inactive volcano at an altitude of $1465 \mathrm{~m}$ rising above the surrounding area, where fields and forest are dominant. The main advantage of the site is the high frequency of the cloud occurrence (50\% of the time on average throughout the year). Westerly and northerly winds are dominant. Meteorological parameters, including the wind speed and direction, temperature, pressure, relative humidity and radiation (global, UV and diffuse), atmospheric trace gases $\left(\mathrm{O}_{3}, \mathrm{NO}_{x}, \mathrm{SO}_{2}, \mathrm{CO}_{2}\right)$ and particulate black carbon (BC) are monitored continuously throughout the year (for more details see Boulon et al., 2011). Long-term studies have been conducted at the site, in particular of aerosol size distribution (Venzac et al., 2009; Rose et al., 2013), aerosol chemical composition (Freney et al., 2011; Bourcier et al., 2012), aerosol optical properties
(Hervo et al., 2014), aerosol hygroscopic properties (Asmi et al., 2012; Holmgren et al., 2014), cloud chemistry (Marinoni et al., 2004; Deguillaume et al., 2014) and cloud microphysics (Mertes et al., 2001).

The ROSEA intercomparison campaign took place from 16 to 28 May 2013 (see Table 1 for the details). Eleven cloudy episodes were sampled, each for several hours. Temperatures were always positive, thus preventing freezing from affecting the measurements. The wind parameters were measured with a Vaisala sonic anemometer and a vane anemometer. Typically, the weather conditions were dominated by westerly winds with speeds ranging from 1 to $22 \mathrm{~m} \mathrm{~s}^{-1}$. The cloud droplet effective diameter ranged between 10 and $30 \mu \mathrm{m}$ and liquid water content (LWC) values were between 0.1 and $1 \mathrm{~g} \mathrm{~m}^{-3}$.

\subsection{Cloud instrumentation and sampling methodology}

A number of instruments were operated simultaneously on the PUY station roof top sampling platform and in the wind tunnel, providing a description of cloud droplets with diameters ranging from a few micrometers up to $50 \mu \mathrm{m}$. Measurements include cloud droplet size distribution, effective diameter, extinction coefficient, LWC and number concentration. This cloud instrumentation is composed of two categories: single particle counters (SPCs) and ensemble-ofparticles probes (EPP). Generally, a SPC uses the forward scattering (usually within the angles interval around 4 to $12^{\circ}$ ) of a laser beam to detect and size individual particles. The size of a particle is deduced from the power of scattered light using Mie theory; and SPCs provide the number concentration for several size bins (Knollenberg, 1981). The obtained cloud droplet size distribution is used to determine cloud microphysical characteristics. The total concentration $N, \mathrm{LWC}$, effective diameter $D_{\text {eff }}$ and extinction coefficient $\sigma$ are computed using the following equations (Cerni, 1983):

$$
\begin{aligned}
& N\left[\mathrm{~cm}^{-3}\right]=\sum_{D} \frac{n(D)}{V_{s}}=\sum_{D} \frac{n(D)}{S \cdot \mathrm{TAS} \cdot \Delta t} \\
& \operatorname{LWC}\left[\mathrm{g} \mathrm{m}^{-3}\right]=\frac{\pi}{6} \cdot \rho_{\mathrm{w}} \cdot \sum_{D} \frac{n(D)}{V_{s}} D^{3} \\
& D_{\mathrm{eff}}[\mu \mathrm{m}]=\frac{\sum_{D} n(D) D^{3}}{\sum_{D} n(D) D^{2}} \\
& \sigma\left[\mathrm{km}^{-1}\right]=Q_{\mathrm{ext}} \cdot \frac{\pi}{4} \cdot \sum_{D} \frac{n(D)}{V_{s}} D^{2},
\end{aligned}
$$

where $n(D)$ is the number concentration measured for the size bin of diameter $D, \rho_{\mathrm{w}}$ is the density of the water. $V_{S}$ is the sampling volume defined as the product of the speed of the air in the inlet TAS (true airspeed), $\Delta t$ is the sampling duration and $S$ is the sampling surface. $S$ is computed as the depth of field (DOF) multiplied by the width of the laser beam. The extinction efficiency $Q_{\text {ext }}$ is considered to be equal to 2 within the droplet size and laser wavelength 
Table 1. Data availability for each instrument used during ROSEA.

\begin{tabular}{|c|c|c|c|c|c|c|c|c|}
\hline \multirow[b]{2}{*}{ Date } & \multicolumn{3}{|c|}{ Wind tunnel } & \multicolumn{5}{|c|}{ Roof } \\
\hline & SPP & CDP 1 & CDP 2 & FSSP & PVM & PWD & FM-100 & Meteorology \\
\hline $16 / 05 / 2013$ & $\sqrt{ }$ & $\sqrt{ }$ & $\sqrt{ }$ & $\sqrt{ }$ & $\mathrm{x}$ & $\sqrt{ }$ & $\sqrt{ }$ & cloudy \\
\hline $17 / 05 / 2013$ & $\mathrm{x}$ & $\mathrm{x}$ & $\mathrm{x}$ & $\sqrt{ }$ & $\sqrt{ }$ & $\sqrt{ }$ & $\sqrt{ }$ & cloudy \\
\hline $19 / 05 / 2013$ & $\mathrm{x}$ & $\mathrm{x}$ & $\mathrm{x}$ & $\sqrt{ }$ & $\sqrt{ }$ & $\sqrt{ }$ & $\sqrt{ }$ & cloudy \\
\hline $20 / 05 / 2013$ & $\mathrm{x}$ & $\mathrm{x}$ & $\mathrm{x}$ & $\sqrt{ }$ & $\sqrt{ }$ & $\sqrt{ }$ & $\sqrt{ }$ & cloudy \\
\hline $21 / 05 / 2013$ & $\mathrm{x}$ & $\mathrm{x}$ & $\mathrm{x}$ & $\sqrt{ }$ & $\mathrm{x}$ & $\sqrt{ }$ & $\sqrt{ }$ & cloudy \\
\hline $22 / 05 / 2013$ & $\sqrt{ }$ & $\sqrt{ }$ & $\mathrm{x}$ & $\sqrt{ }$ & $\mathrm{x}$ & $\sqrt{ }$ & $\sqrt{ }$ & cloudy \\
\hline $23 / 05 / 2013$ & $\mathrm{x}$ & $\mathrm{x}$ & $\mathrm{x}$ & $\mathrm{x}$ & $\sim$ & $\sqrt{ }$ & $\sqrt{ }$ & cloudy \\
\hline $24 / 05 / 2013$ & $\sqrt{ }$ & $\sqrt{ }$ & $\mathrm{x}$ & $\mathrm{x}$ & $\mathrm{x}$ & $\sqrt{ }$ & $\sqrt{ }$ & cloudy \\
\hline $25 / 05 / 2013$ & $\mathrm{x}$ & $\mathrm{x}$ & $\mathrm{x}$ & $\mathrm{x}$ & $\sqrt{ }$ & $\sqrt{ }$ & $\sqrt{ }$ & cloudy \\
\hline $26 / 05 / 2013$ & $\mathrm{x}$ & $\mathrm{x}$ & $\mathrm{x}$ & $\mathrm{x}$ & $\sqrt{ }$ & $\sqrt{ }$ & $\sqrt{ }$ & cloudy \\
\hline $27 / 05 / 2013$ & $\mathrm{x}$ & $\mathrm{x}$ & $\mathrm{x}$ & $\sqrt{ }$ & $\sqrt{ }$ & $\sqrt{ }$ & $\sqrt{ }$ & clear \\
\hline $28 / 05 / 2013$ & $\sqrt{ }$ & $\sqrt{ }$ & $\mathrm{x}$ & $\sqrt{ }$ & $\sqrt{ }$ & $\sqrt{ }$ & $\sqrt{ }$ & cloudy \\
\hline
\end{tabular}

range. Since the measurement principle is similar for all SPC instruments, the uncertainty in normal conditions is broadly the same: the concentration and LWC have uncertainties of 20 and $30 \%$, respectively (Baumgardner, 1983; Fevbre et al., 2012). Most of the SPCs are calibrated for size measurements but not for number concentration measurements. Some of the major sources of uncertainties specific to SPCs include (see Baumgardner et al., 1985; Brenguier, 1998; Lance et al., 2010 for more details) the following.

- Size resolution limits due to Mie resonance: since the same scattered energy can match with several particle sizes, the sizing resolution is limited. For this reason, the cloud particle sizing has an uncertainty of one size bin, which corresponds to values between 2 and $3 \mu \mathrm{m}$ depending on the size calibration.

- Electronic delays: the dead time, necessary for the electronic system to treat the data has to be taken into account for some SPCs. The sampling duration $\Delta t$ is corrected by a factor lower than 1 . That factor, usually called "activity", accounts for the losses due to instrument dead time. On the other hand, recent instruments have an improved electronic system and are free from such kind of uncertainty.

- Coincidence: it occurs when two or more droplets are in the sampling volume at the same time. It is thus strongly concentration dependent and is the most important uncertainty for high concentrations.

- Splashing and shattering: during in-flight experiments, a particle can be broken on the inlet and results in a false increase in smaller droplets. The uncertainty associated with splashing/shattering is low for measurements in clouds having small droplets.
- Particle velocity: the TAS is approximated by the speed of droplets passing through the laser beam. Uncertainties in droplet velocity lead to errors in the computation of the sampling volume.

- Changing velocity acceptance ratio (VAR) (Wendisch, 1998): this stems from the fact that only a part of the laser beam diameter is used to calculate the sampling volume because drops passing the laser beam near its edges are undersized. Theoretically, by electronic procedure consisting in a threshold in the transit time, only $62 \%$ of the laser beam diameter is used to accept a particle. This value has to be taken into account in the sampling-surface calculation and it can change with time. Thus, the VAR has to be measured and the actual value has to be used in the data processing.

- Sampling volume assessment: this is affected by errors in the sampling speed, the laser width, and the depth of field (DOF). Usually, all these errors are very difficult to quantify and extreme uncertainty can be very high. For example, Burnet and Brenguier (2002) reported that the DOF of the FSSP could be significantly different from the value given by the manufacturer; this difference may reach a factor 2 .

The SPCs used during the intercomparison campaign are a Forward Scattering Spectrometer Probe (PMS FSSP-100), a Fast FSSP (SPP-100), a Fog Monitor (DMT FM-100) and two Cloud Particle Probes (DMT CDP).

The Forward Scattering Spectrometer Probe (FSSP100) initially manufactured by Particle Measuring Systems (PMS), Inc. of Boulder, Colorado is the oldest instrument still in use for measuring cloud droplet size distribution. It uses a laser at the wavelength of $\lambda=0.633 \mu \mathrm{m}$. Electronic delays and changing VAR corrections need to be accounted 
for in the FSSP data processing. The operation, the uncertainty, the limitations and the corrections are detailed by Dye and Baumgardner (1984), Baumgardner et al. (1985) and Baumgardner and Spowart (1990). For water droplet clouds, the uncertainty of the derived effective diameter and LWC was estimated as $3 \mu \mathrm{m}$ and $30 \%$, respectively (Febvre et al., 2012). According to Gayet et al. (1996), errors in particle concentration can reach 20 to $30 \%$. In the operating range used at the PUY, the resulting counts were summarized into 15 diameter bins, each of $3 \mu \mathrm{m}$ width, beginning from $2 \mu \mathrm{m}$ and ending at $47 \mu \mathrm{m}$. During the intercomparison, a commercial pump was employed to aspirate a constant air flow through the FSSP-100. The flow through the pump was monitored with a mass flow anemometer. The air flow speed was set to around $15 \mathrm{~m} \mathrm{~s}^{-1}$. Theoretically, this flow leads to an air speed through the FSSP-100 inlet of $9 \mathrm{~m} \mathrm{~s}^{-1}$; that value was employed for the data processing. The FSSP was checked periodically to keep the inlet facing into the wind. It should be mentioned that no conical attachment (horn) was mounted on the instrument during this campaign. It means that the air suction into the FSSP inlet tube can generate curved streamlines leading to potential inertial concentration effects (Gerber et al., 1999).

The SPP-100 is a modified model of the FSSP-100 (manufactured by Droplet Measurement Technologies DMT, Inc., Boulder, USA) with 40 size bins and a revised signalprocessing package (fast-response electronic components). Brenguier et al. $(1998,2011)$ have shown that the SSP-100 noticeably improves the accuracy of the size distribution assessment compared to the FSSP-100 version. The electronic system of the SPP-100 is fast enough to neglect the electronic delay; but the data processing still needs regular VAR corrections.

The Fog Monitor (FM-100) is a Forward Scattering Spectrometer Probe $(\lambda=0.658 \mu \mathrm{m})$ placed in its own wind tunnel with active ventilation (Eugster et al., 2006), manufactured by Droplet Measurement Technologies (DMT), Inc., Boulder, USA. The design of the transport tubing (consisting of a contraction part and a wind tunnel) reduces mean flow problems during the sampling and make the FM-100 designed for ground-based studies. For the ROSEA experiments, we used a resolution of 20 channels to describe the size distribution with a diameter range between 2 and $50 \mu \mathrm{m}$. Details of the operation of this instrument are given by Droplet Measurement Technologies (2011). According to Spiegel et al. (2012), in extreme conditions such as misalignment with the wind direction, uncertainties in concentration resulting from particle losses, i.e., sampling losses and losses within the FM-100 (such as turbulent deposition, sedimentation and inertial losses in contraction) can be as high as $100 \%$. The FM-100 has a pitot tube to measure the air speed used in the sampling volume computation. However, as it did not work during the campaign, the sampling speed was set to the constant theoretical value of $15 \mathrm{~m} \mathrm{~s}^{-1}$. This assumption adds uncertainties to the FM sampling volume.
The CDP is a forward-scattering optical spectrometer $(\lambda=$ $0.658 \mu \mathrm{m})$, manufactured by DMT. According to Lance et al. (2010), coincidence can be significant for concentrations as low as $200 \mathrm{~cm}^{-3}$. While an oversizing of $60 \%$ and undercounting of $50 \%$ have been quantified at droplet concentrations of $400 \mathrm{~cm}^{-3}$. The CDP has no electronic delay but data processing needs regular VAR corrections. As a result of Mie oscillations, some size bins were grouped to a total of 24 size bins, from 3 to $49 \mu \mathrm{m}$. Two types of CDP were used during the campaign: the first version (CDP1) with original tips and the second version (CDP2) with Korolev tips against possible shattering effects. For both versions no pin hole for reducing coincidence effects was added on the sizer of the CDP.

The second type of instruments used during the intercomparison campaign is the ensemble-of-particles probes (EPP). These instruments sample a large number of particles and measure bulk-average parameters. Particle size distributions are not available. The EPP instrumentation of the campaign was composed of a Particle Volume Monitor (PVM-100) and a Present Weather Detector (PWD-22).

The Particle Volume Monitor (PVM-100, manufactured by Gerber Scientific, Inc., Reston, Virginia) is a ground-based forward-scattering laser spectrometer for particulate volume measurements (Gerber, 1984, 1991). It is designed to measure the LWC, the particle surface area (PSA) and to derive the droplet effective radius $\left(r_{\text {eff }}\right)$. The PVM-100 measures the laser light $(\lambda=0.780 \mu \mathrm{m})$ scattered in the forward direction by an ensemble of cloud droplets which crosses the probe's sampling volume of $3 \mathrm{~cm}^{-3}$. The light scattered in the 0.25 to $5.2^{\circ}$ angle range is collected by a system of lenses and directed through two spatial filters. The first filter converts scattered light to a signal proportional to the particle volume density (or LWC) of droplets; the second filter produces a signal proportional to the particle surface area density (PSA) (Gerber et al., 1994). From the ratio of these two quantities, $r_{\text {eff }}$ can be derived:

$r_{\mathrm{eff}}=\frac{\mathrm{LWC}}{3 \sigma}$.

These two filters guarantee a linear relationship between scattering intensity and LWC or PSA for droplets diameter from 3 to $45 \mu \mathrm{m}$ for the PVM-100 (Gerber, 1991). The extinction coefficient $\sigma$ is directly proportional to the PSA:

$\sigma\left[\mathrm{km}^{-1}\right]=0.05 \cdot \operatorname{PSA}\left[\mathrm{cm}^{2} \mathrm{~m}^{-3}\right]$.

According to Gerber et al. (1994), the uncertainty of LWC is $10 \%$ for this diameter range. The airborne version of the PVM is the PVM-100A which has a different set of filters to enhance sampling volume resulting in a reduced sensitivity to larger droplets. Wendisch et al. (2002) reported higher errors, up to $50 \%$, when the mean volume diameter (MVD) exceeds $25 \mu \mathrm{m}$.

The Present Weather Detector (PWD22) is a multivariable sensor for automatic weather observing systems. 
The sensor combines the functions of a forward scatter visibility meter and a present weather sensor. PWD22 can measure the intensity and the amount of both liquid and solid precipitation. As the detector is equipped with a background luminance sensor, it can also measure the ambient light (Vaisala, 2004). This instrument provides the visibility or Meteorological Optical Range (MOR), which is a measure of the distance at which an object or light can be clearly discerned and from which we can deduce the extinction coefficient $\sigma$ by (Vaisala, 2004)

$\sigma\left[\mathrm{km}^{-1}\right]=\frac{3000}{\operatorname{MOR}[\mathrm{m}]}$

According to Vaisala (2004), the uncertainty of the MOR and $\sigma$ is $10 \%$.

The FSSP-100, the FM-100, the PWD and the PVM-100 were operated on the roof of the station, at approximately $2 \mathrm{~m}$ above the platform level (see Fig. 1a). The FSSP and the FM-100 were mounted on a tilting and rotating mast, allowing them to be moved manually in the dominating wind direction. The proper alignment of their inlet with the flow was based on the wind direction measurements performed by a mechanical and ultrasonic anemometer placed on a separate mast fixed on the terrace of the PUY station. The data availability of these instruments is shown in Table 1.

In addition to the continuous measurements performed on the roof of the station, the PUY research station is also equipped with an open wind tunnel located on the west side of the building. The wind tunnel consists of a sampling section, $2 \mathrm{~m}$ in length, with an adjustable airflow up to $17 \mathrm{~m}^{3} \mathrm{~s}^{-1}$, corresponding to the airspeed of $55 \mathrm{~m} \mathrm{~s}^{-1}$. The applied air speed inside the wind tunnel was between 10 and $55 \mathrm{~m} \mathrm{~s}^{-1}$. The method of an icing grid (see e.g., Irvine et al. 2001) was used for airflow uniformity measurements. The tests were performed at the maximal airspeed available in the wind tunnel. According to the preliminary results, the variations of the thicknesses and widths of the iced bands were lower than $5 \%$, i.e., of the order of the uncertainty of the method. Thus, we can reject the hypothesis of the airflow heterogeneity as the cause of the differences between the microphysical measurement data. For additional information about the site description, see Bain and Gayet (1983) and Wobrock et al. (2001). During the campaign, a Forward Scattering Spectrometer Probe SPP-100 model and two Cloud Droplet Probes (CDP1 and CDP2) were installed in the sampling section of the wind tunnel (see Fig. 1b) to characterize the cloud microphysical properties in terms of droplet size distributions and extinction coefficients. Four experiments were performed in the wind tunnel, each with the duration of nearly $2 \mathrm{~h}$ (see Table 1 ).

During the campaign, instruments collected data at a frequency of $1 \mathrm{~Hz}$. In order to synchronize measurements from multiple instruments, data have been averaged over $10 \mathrm{~s}$ or $1 \mathrm{~min}$. The length of the averaging time depends on the duration of the experiment, and cloud heterogeneity. The PVM

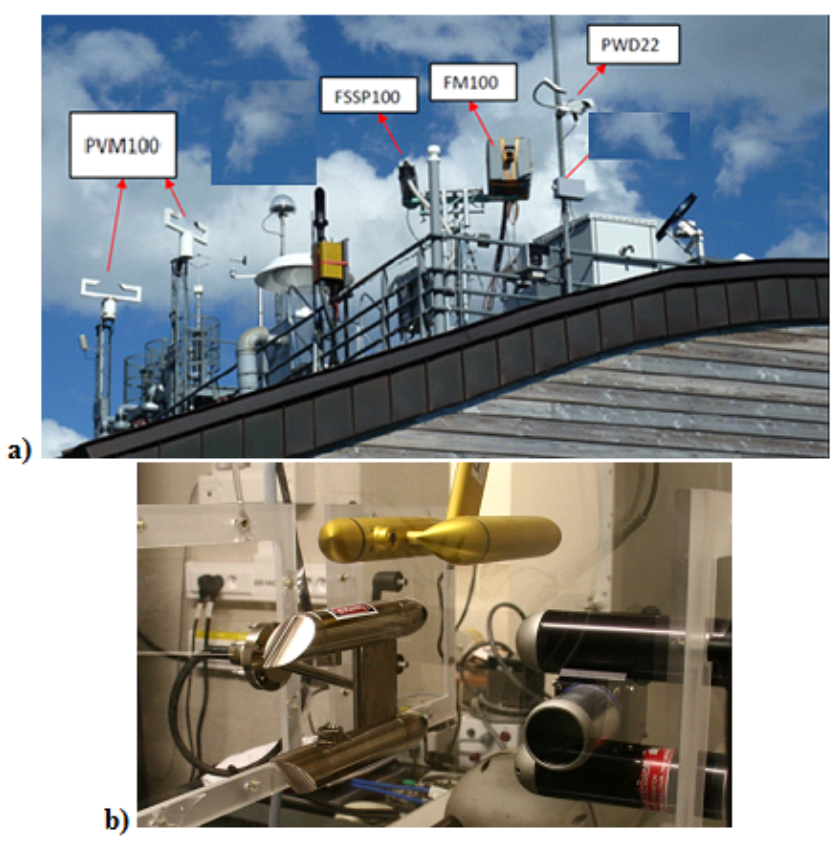

Figure 1. (a) Instruments set up on the roof. The FSSP and the FM100 were placed on the mast, which can be oriented manually, so the direction in which these two instruments are pointed can be chosen and (b) instruments set up in the wind tunnel: the SPP on the right, the CDP 1 on the top and the CDP 2 on the left.

measurements are provided with routine protocol which averaged data over $5 \mathrm{~min}$; thus any comparison with this instrument has to be carried out with $5 \mathrm{~min}$ average data. The FSSP shows incoherent measurements from 23 to 26 March, probably due to electronic interferences. An overview of the data availability during the campaign is shown in Table 1. The SPCs were calibrated in size using glass beads, between the 22 and 29 April 2013 before the campaign, and between the 8 and 30 November 2013 after the campaign. The EPPs were calibrated using opaque disk a few days before the beginning of the campaign. The data unavailability is caused by the absence of experiments in the wind tunnel and instrumental problems on the roof. A summary of the instrument characteristics, with uncertainties in normal and extreme conditions, is reported on Table 2.

\section{Results and discussion}

\subsection{Data analysis strategy based on a preliminary case study}

The purpose of this section is to give an overview of the microphysical measurement strategy performed during the campaign with a focus on the instrument variability. During the 16 May a large number of instruments were deployed simultaneously on the station platform and in the wind tunnel (see Table 1). 
Table 2. Instrumental set-up during the ROSEA intercomparison campaign at the Puy-de-Dôme. Uncertainties in normal and extreme conditions are presented. Reff is the effective radius.

\begin{tabular}{|c|c|c|c|c|c|}
\hline Instrument & $\begin{array}{l}\text { Measured } \\
\text { parameter(s) }\end{array}$ & $\begin{array}{l}\text { Measurement } \\
\text { range }\end{array}$ & $\begin{array}{l}\text { Accuracy: normal } \\
\text { conditions }\end{array}$ & $\begin{array}{l}\text { Accuracy: extreme } \\
\text { conditions }\end{array}$ & $\begin{array}{l}\text { Time } \\
\text { resolution }\end{array}$ \\
\hline \multicolumn{6}{|l|}{ Forward Scattering Spectrometer } \\
\hline Probe (FSSP \& SPP) & size distribution & $2-47 \mu \mathrm{m}$ & $\begin{array}{l}\text { D: } \pm 3 \mu \mathrm{m} \\
\text { Number conc. : } \pm 20 \%\end{array}$ & - & $1 \mathrm{~s}$ \\
\hline Fog Monitor (FM) & size distribution & $2-50 \mu \mathrm{m}$ & $\begin{array}{l}\text { D: } \pm 3 \mu \mathrm{m} \\
\text { Number conc. : } \pm 20 \%\end{array}$ & $\begin{array}{l}\text { Number conc. : } \pm 100 \% \text {, } \\
\text { Spiegel et al. (2012) }\end{array}$ & $1 \mathrm{~s}$ \\
\hline Cloud Droplet Probe (CDP) & size distribution & $2-50 \mu \mathrm{m}$ & $\begin{array}{l}\text { D: } \pm 3 \mu \mathrm{m} \\
\text { Number conc. : } \pm 20 \%\end{array}$ & $\begin{array}{l}\text { Number conc. : } \pm 50 \% \text {, } \\
\text { Lance et al. }(2010)\end{array}$ & $1 \mathrm{~s}$ \\
\hline Particle Volume Monitor (PVM) & extinction, LWC, Reff & $3-45 \mu \mathrm{m}$ & LWC: $\pm 10 \%$ & $\begin{array}{l}\text { LWC: } \pm 50 \% \text {, } \\
\text { Wendish et al. (2002) }\end{array}$ & $5 \mathrm{~min}$ \\
\hline Present Weather Detector (PWD 22) & extinction & all & $\pm 10 \%$ & - & $1 \mathrm{~min}$ \\
\hline
\end{tabular}

Figure 2 provides an example of the temporal evolution of the parameters measured the 16 May. On this graph, we choose to represent only the time series of the cloud properties averaged over $10 \mathrm{~s}$ when the wind tunnel was actually functioning. According to Table 1, the PVM did not properly function on this particular day. The wind speed outside and inside the wind tunnel is shown in Fig. 2a. The outside wind speed varied from 2 to $7 \mathrm{~m} \mathrm{~s}^{-1}$, while the air speed in the wind tunnel was set up to fixed values ranging from 25 to $55 \mathrm{~m} \mathrm{~s}^{-1}$. The measured cloud parameters displayed in Fig. $2 b-d$ are the effective diameter, the number concentration and the liquid water content of cloud droplets measured by the FSSP and the FM on the roof of the PUY station as well as those ones obtained from the two CDPs and the SPP located in the wind tunnel. The time series of the extinction coefficient derived from these instruments are shown in Fig. 2e. The observed cloud layers were above the freezing level with temperatures almost constant around $1{ }^{\circ} \mathrm{C}$. During the sampling period, the dominant wind was blowing westward and the instruments positioned on the mast were oriented accordingly.

The values and the variability of the effective diameter measured by the instruments are in good agreement with a correlation coefficient close to 0.9 (Fig. 2b).

Although the microphysical properties' variability is well captured by all the instruments (correlation coefficient close to 0.9 ), the temporal evolution of the number concentration exhibits systematic differences among the instruments (Fig. 2c). The number concentration measured by the FM100 is systematically lower than that one derived from the other instruments, while the FSSPs (SPP and FSSP-100) show the highest values. The ratio between the concentration measured by the FM and the FSSPs reaches values up to 5. As for the CDPs installed in the wind tunnel, the concentration measurements lie between the values obtained by the FSSPs and the FM-100. The two CDPs have a ratio of 1.35 and the CDP 1 has values close (ratio of 1.6) to those of the FM-100. Similarly, the LWC and extinction coefficient values show significant discrepancies. The measured cloud

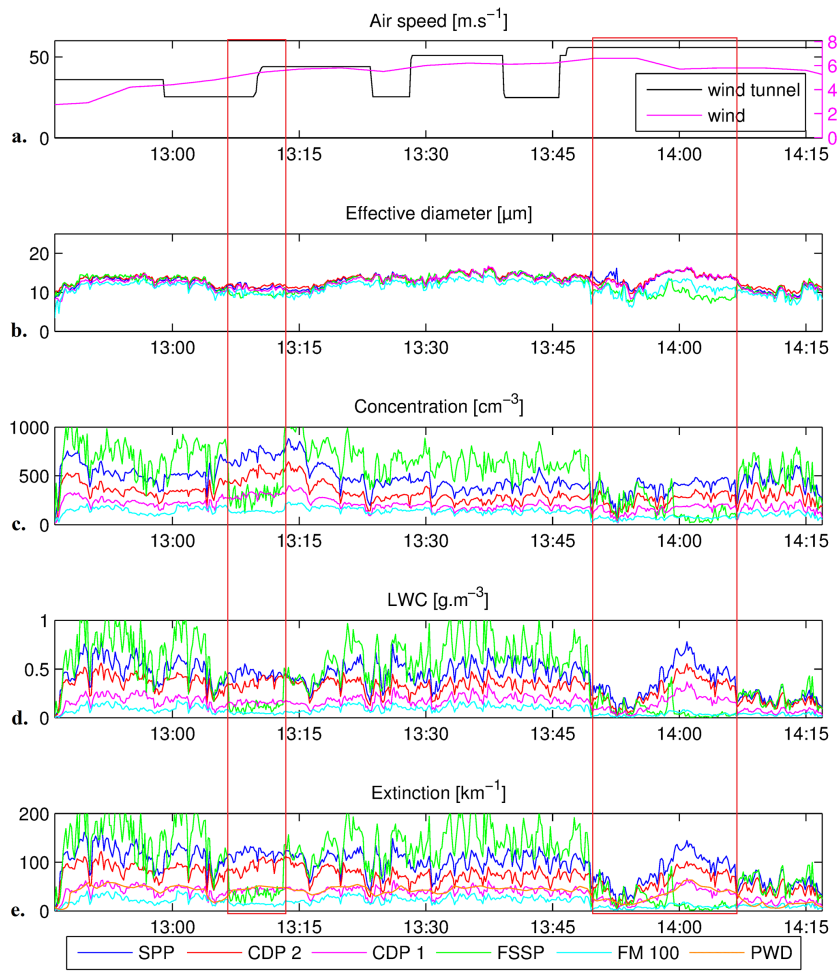

Figure 2. Time series of the 16 May experiment of the main measured parameters: (a) ambient wind speed (purple) and wind tunnel air speed (black); (b) effective diameter; (c) concentration; (d) LWC and (e) extinction. The data are $10 \mathrm{~s}$ averaged, except for the PWD measurements performed with a 1 min time resolution. The red-framed parts of the time series correspond to additional experiments where the orientation of the instruments on the mast was changed (for the FM-100 and the FSSP).

droplet extinctions vary up to a factor of 2.5 (FSSP) and 0.55 (FM-100) compared to the PWD. The bias between the instruments is potentially very important (up to 5 when comparing the FSSPs extinction to the FM-100). However, the temporal variability of the data shows good correlation $\left(R^{2}\right.$ close to 0.9). 
The red-framed parts of the time series displayed in Fig. 2 correspond to additional experiments where the orientation of the instruments on the mast was changed (the FM-100 and the FSSP). Those orientation changes lead to a sudden decrease of all the microphysics parameters of the instruments installed on the mast, especially of the FSSP. The data corresponding to those orientation experiments are removed for the following analysis and will be discussed in the Sect. 3.4. On the example of 16 May, we observe that the differences in concentrations measured with different probes seem to vary, and may be a function of wind speed and direction.

This example illustrates that the probes' adequate sizing of cloud droplets is subject to a systematic bias when particle counting (number concentration) is involved. This can be clearly seen in Fig. 3 where the average particle size distributions (PSDs) in concentration, surface and LWC measured by the different spectrometer probes are displayed. It should be noted that these average PSDs were obtained when the probe orientations were coaxial with the wind direction. The PSDs in number is a good indicator of the small droplets concentration while the PSDs in surface and volume are more representative of droplets with intermediate and large sizes, respectively.

The PSDs show similar trends and shapes, with size modes from 10 to $14 \mu \mathrm{m}$ which explains the agreement in the effective diameter values. The FSSP number PSD show a clear overestimation for the particles smaller than $10 \mu \mathrm{m}$, compared to all the other instruments. This could be partly attributed to an enhancement of small droplets in the sampling volume of the FSSP due to super-kinetic sampling. The computed average mean volume diameter (MVD) shows similar values with a maximum deviation of $1.3 \mu \mathrm{m}$, which is within the instrumental errors. This confirms the good agreement of mean size for all instruments. However, the discrepancies observed in the measured droplet concentration of the PSD are significant and linked to the systematic concentration bias evidenced in Fig. 2. This means that the size bins' partitioning is correct and the number concentration discrepancies are likely to come from an incorrect assessment of the probe sampling volume. In addition, the SPP-100 tends to overestimate the number concentration for the largest particles (larger than $30 \mu \mathrm{m}$ ), compared to the other instruments, especially for the two CDPs of the wind tunnel. One possible explanation could be the effect of splashing artifacts inside the SPP inlet, as evidenced by Rogers et al. (2006). This result highlights the difficulties of accurately deriving the droplets concentration, which was expected due to the lack of simple number calibration for these instruments.

\subsection{Instrumental intercomparison for wind-isoaxial conditions}

In this section, we focus on measurements performed in the wind tunnel and on the roof of the station when the wind was isoaxial to the sampling probes inlets, over the whole cam-
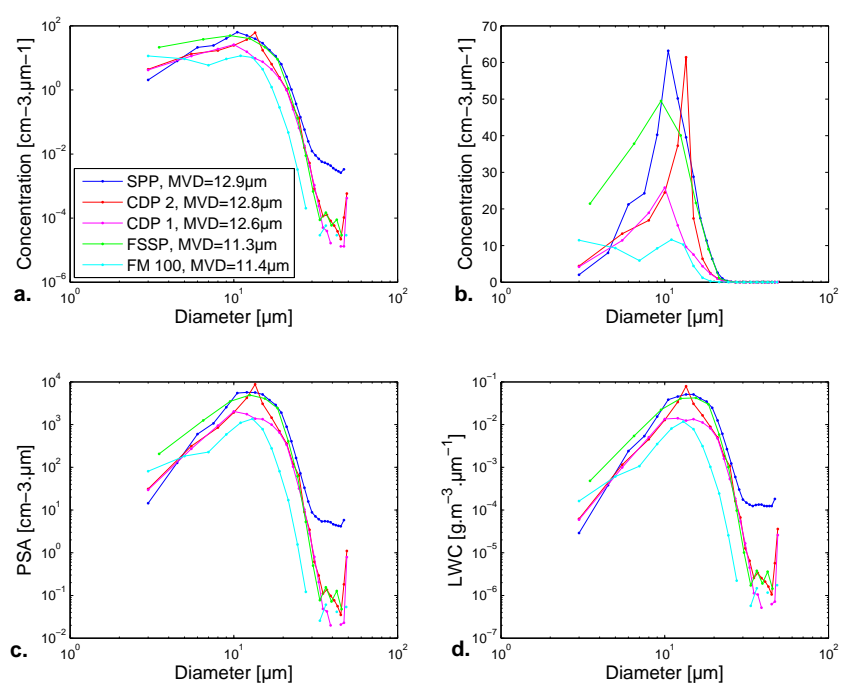

Figure 3. Averaged size distribution in concentration, with (a) logarithmic and (b) linear scale, (c) surface and (d) LWC for the 16 May over the period of time shown in Fig. 1 (i.e., 12:46 to 14:17). The colors correspond to the different instruments displayed in the legend. The data have been selected for wind coaxial measurements. The average median volume diameter MVD is also shown.

paign. Microphysical changes, due to the orientation of the instruments, observed in Fig. 2, will not be analyzed here. The data are averaged over $10 \mathrm{~s}$ for the wind tunnel measurements and over $1 \mathrm{~min}$ for ambient conditions in order to make the measurements comparable (see Sect. 2.3).

Figure 4 displays the scatter plots of the effective diameter for the instruments deployed on the PUY platform. The dashed lines show the uncertainties applied to the linear fit; the errors considered for each instrument are given in Table 2 for normal conditions. There is a good agreement between the FM-100 and the FSSP with a high linear correlation coefficient value $\left(R^{2}=0.94\right)$. Additionally, the bias observed between these two instruments is within the "theoretical" measurement errors. The comparison between the PVM, the FSSP and the FM-100 shows that the overall variability of cloud droplet effective diameter is well captured $\left(R^{2}\right.$ close to 0.9 ). Even if the slope of the linear regression is greater than 1 , the measurement points are close to the line $1: 1$ and the scatter is within the measurement uncertainties. Moreover, the comparisons (not shown here) between the PVM and the FM-100 extinction and LWC give a slope $a$ of 2.1 with $R^{2}=0.72$ and $a=2.6$ with $R^{2}=0.78$, respectively. When comparing the PVM and the FSSP 100 the slopes are $a=0.35$ with $R^{2}=0.65$ and $a=0.4$ with $R^{2}=0.8$ for the extinction and the LWC, respectively. The rather good correlations obtained between the instruments can be explained by the agreement of the effective diameter and size distribution shape for the different instruments.

The comparison between the number concentrations measured coaxially to the wind direction by the FSSP and the 

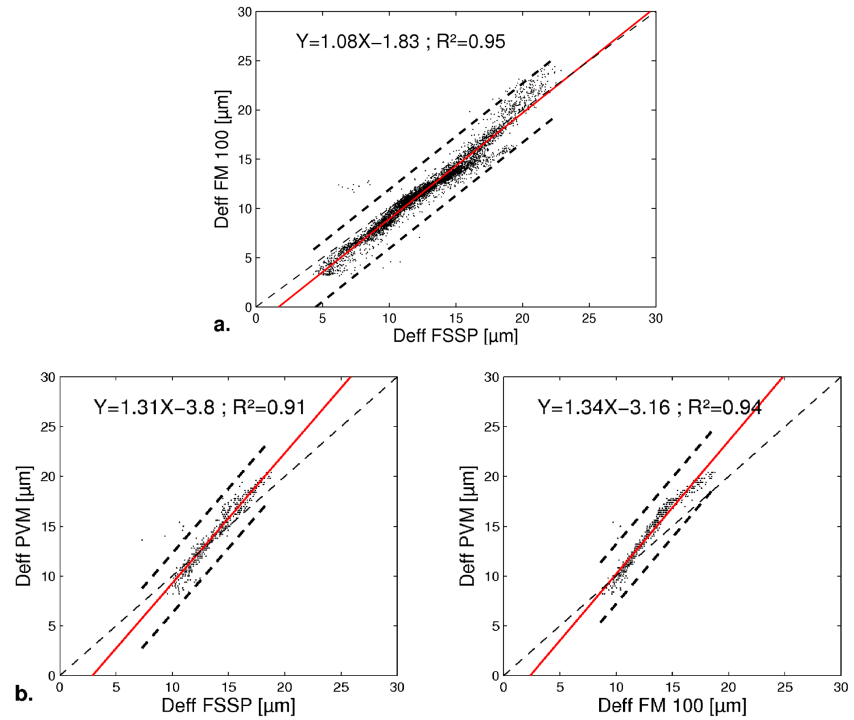

Figure 4. (a) Comparison between the 1 min averaged effective diameters of the FM-100 and the FSSP. (b) Comparison between the 5 min averaged effective diameters between the PVM and the FSSP (left) and with the FM-100 (right). The bold dashed lines show the instrumental errors applied to the fit.

FM-100 over the whole campaign is displayed in Fig. 5. The concentration measurements are slightly less correlated than the effective diameter measurements but the correlation remains acceptable $\left(R^{2}=0.8\right)$ and most of the points remain in the uncertainty area. However, a significant discrepancy (slope of 0.18 which corresponds to a factor 5.5) between the instrument concentration measurements is clearly evidenced. This ratio is the same as that one obtained when LWC are compared (not shown), thus confirming that the sizing is coherent between the two instruments. The constant bias found for the concentration affects the extinction and the LWC in the same way. We recall that the FSSP was observed to overestimate small particles and that the FM-100 sampling speed was set to a constant value of $15 \mathrm{~m} \mathrm{~s}^{-1}$ because the speed measured by the pitot tube was unreliable. This can explain the observed differences between measurements. We observe that measurements performed under low wind speed (lower than $5 \mathrm{~m} \mathrm{~s}^{-1}$ ) are more scattered compared to those made at high wind speed (Fig. 5). This will be discussed in more detail in Sect. 4.

A comparison between the 5 min averaged extinction coefficients measured by the PVM and the PWD, two instruments that do not need active ventilation, is shown in Fig. 6. There is a good agreement $\left(R^{2}=0.86\right)$ and a slope close to 1 . The small discrepancies between these two instruments can be attributed to the heterogeneity of the cloud properties and instrumental errors. The points with the low extinction values show largest variations, corresponding to the cloud edge where the properties are the most heterogeneous.

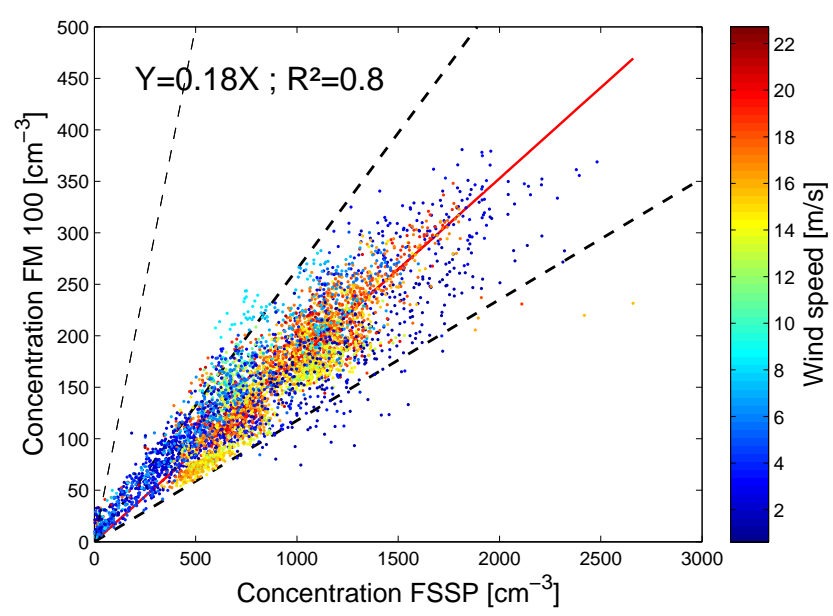

Figure 5. One minute averaged concentration in $\mathrm{cm}^{-3}$; measurements were obtained from the FM-100 as a function of the FSSP concentration of the FSSP. The colors show the values of the wind speed. The bold dashed lines show the instrumental errors applied to the fit. The $99 \%$ confidence interval of the slope value was estimated to be $[0.177,0.183]$.

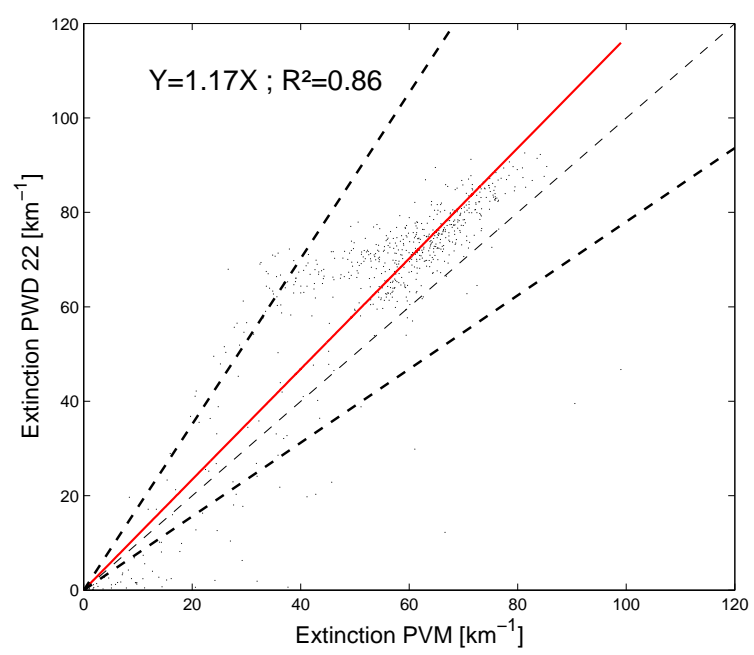

Figure 6. Scatter plot of the PWD and PVM 5 min average extinction coefficients. The bold dashed lines show the instrumental errors applied to the fit. The $99 \%$ confidence interval of the slope value was estimated to be $[1.156,1.184]$.

Therefore, the fact that there is a systematic constant bias (factor of 6 in Fig. 5) in the intercomparison of the droplet number concentration and of the LWC, measured by the different probes, could be indicative of the inaccurate assessment of the probe sampling volume directly linked to the air flow speed measurement accuracy. In order to discuss this issue, the measurements performed under ambient conditions are compared with the measurements in the wind tunnel where the sampling speed is recorded more accurately than in ambient air. 
Figure $7 \mathrm{a}$ presents the results of the effective diameter as the intercomparisons for the three instruments installed in the wind tunnel. Good agreement is observed among the probes, with correlation coefficients $R^{2}$ always higher than 0.9 . The slope of the linear regression is close to 1 , meaning that the assessment of this parameter is consistent for the CDPs and the SPP-100, thus confirming the good calibration in diameter.

The measured droplet concentrations (Fig. 7b) also show high correlation coefficients $\left(R^{2}=0.9\right)$, comparable to those measured for the effective diameter. However, linear regression analysis shows that the concentration ratio may reach a factor of 2 for the different instruments. It should be noted that these slopes are independent of the air speed applied in the wind tunnel. Even though the discrepancies are less pronounced than those ones for the instruments placed on the platform of the PUY station, a significant bias still exists. This bias may be attributed to the assessment of the probe sampling speed/volume. However, when the biases are taken into account, at least $90 \%$ of the points are within the uncertainty area.

The bias between the instruments results from systematic errors of the assessment of the sampling volume. The single particle counters (SPCs) have uncertainties in optical parameters such as the DOF and in corrections like the activity. In addition, the data of the ground-based FM and FSSP are affected by errors of the sampling speed assessment. In order to evaluate the consistency of measurements performed in ambient air (on the mast) with those performed in a windcontrolled environment, we characterized the relative sensitivity of the droplet concentration measurements to different wind speeds. As already discussed, all the instruments in the wind tunnel are very well correlated. Since only the slope of the linear regression differs from one instrument to another, we chose to compare the FSSP and the FM-100 sampling on the roof, with the SPP100 sampling in the wind tunnel. These instruments are based on the same measurement principle.

Figure 8 displays the scatter plots of the number concentration measured by the instruments on the mast against the SPP observations performed during the four wind tunnel experiments (the 16, 22, 24 and 28 May with the $10 \mathrm{~s}$ average measurements). The concentrations measured by the FM-100 are well correlated to the SPP observations even though the wind speeds are quite different, ranging from 2 to $21 \mathrm{~m} \mathrm{~s}^{-1}$ for external wind and from 10 to $55 \mathrm{~m} \mathrm{~s}^{-1}$ in the wind tunnel. Additionally there is no clear dependence of the measurements on the wind speed. We can thus conclude that the FM-100, the SPP-100 and the CDPs' coaxial measurements do not seem to depend on the air speed values (ambient wind speed or applied in the wind tunnel). However, a factor of 4 is found between the concentrations measured on the roof by the FM-100 and by the SSP in the wind tunnel (factor of 3 when compared to the CDP1). These high discrepancies can be explained by the sampling volume uncertainties (including errors in the DOF and the sampling speed that can
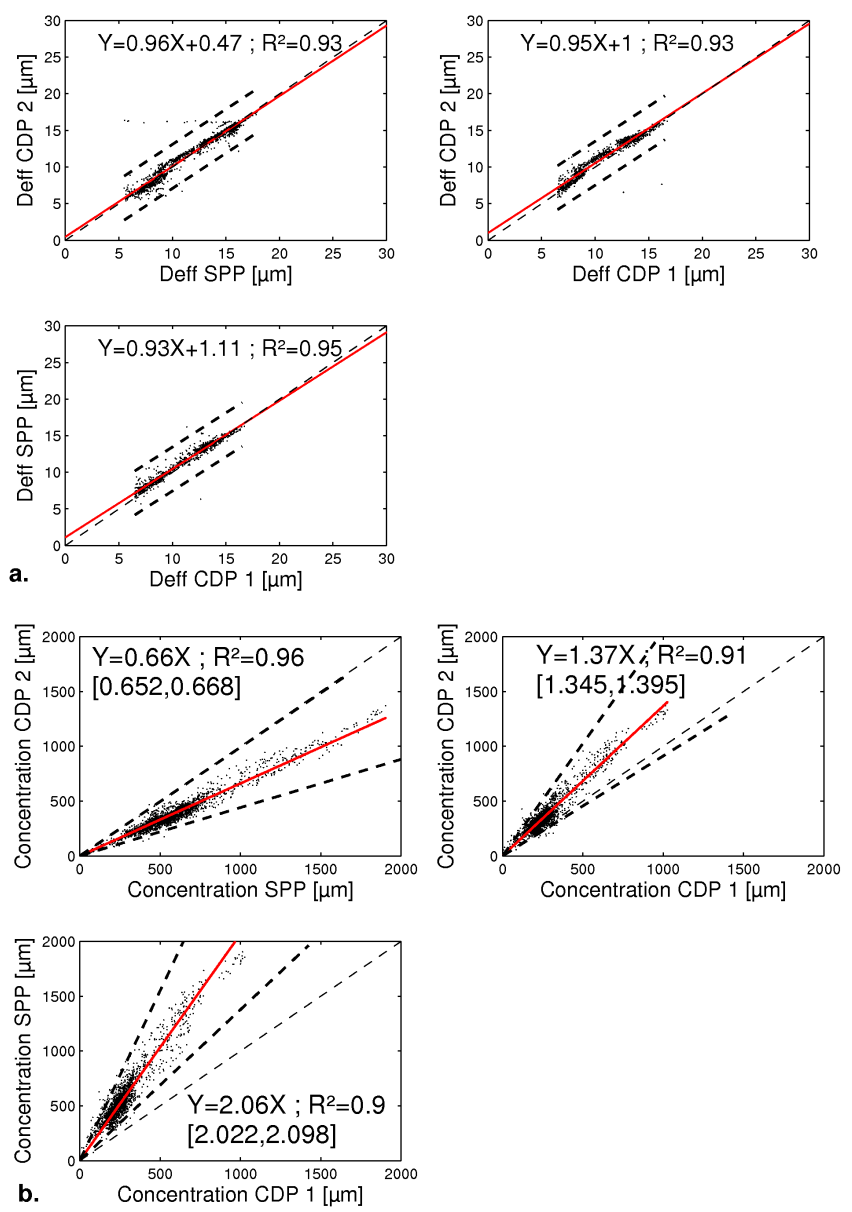

Figure 7. (a) Ten second averaged data comparison of the effective diameter measured by the instruments installed in the wind tunnel, i.e., the CDP1, the CDP2 and the SPP; and (b) 10 s averaged data comparison of the concentration measured by the instruments installed in the wind tunnel. The confidence intervals with a confidence level of $99 \%$ are given in square brackets. The bold dashed lines show the instrumental errors applied to the fits.
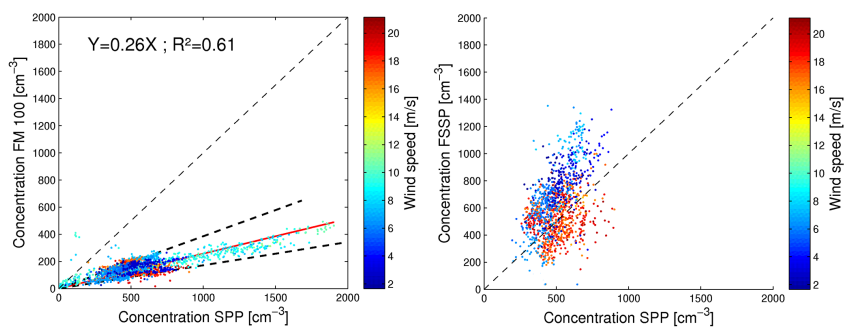

Figure 8. Scatter plots of the $10 \mathrm{~s}$ averaged concentrations measured by the FM-100 (left) and the FSSP (right), in ambient conditions, with the wind tunnel SPP. The colors reveal the ambient wind speed. The bold dashed lines show the instrumental errors applied to the fit. The $99 \%$ confidence interval of the slope value was estimated to be [0.251, 0.269]. 
reach $100 \%$ ), instrumental errors (around $20-30 \%$ in the concentrations for most of the instruments), potential turbulent and/or anisokinetic flow and the cloud inhomogeneity.

However, the $10 \mathrm{~s}$ average FSSP measurements exhibit a high variability and show no correlation with the SPP observations. Both, the inter- and intra-experiment variability is significant, meaning that correction of global data is not possible. Additionally, due to some instrument data availability (see Table 1), the correlation plots relative to the FSSP and the FM-100 are not directly comparable. The 24 May experiment is not available for the FSSP but shows a large variability in concentration, which results in an increase in the correlation of the FM-100 compared to the FSSP. However, as the FM-100 was designed for ground-based measurements, it is not surprising that the FM-100 measurements are more in agreement with the other instruments of the wind tunnel than the FSSP. On the contrary, anisokinetic sampling of the FSSP leads to higher discrepancies when this instrument is compared to other ones.

The droplet diameter and concentration intercomparisons show that the uncertainties linked to the calibration and to the calculation of the sampling volume lead to systematic biases similar to the measurement of concentration, extinction and LWC. The agreement observed between the FM-100, the SPP and the CDP measurements indicates that these data could be standardized on the basis of a reference instrument, with a simple relation of proportionality that would be valid for the entire campaign. However, particular attention should be addressed to the FSSP measurements which were shown to be sensitive to wind conditions. Therefore, the remainder of this study will focus on the standardization of the results, on biases correction for isoaxial measurements as well as on the study of the effect of the air speed (wind speed or suction in the wind tunnel) on the measurements.

To summarize this section, the comparisons showed good correlations between the deduced parameters, that is, good sizing for all the instruments. At the same time, the instruments displayed large discrepancies in their capability to assess the cloud droplet number concentrations. As the FSSP is aspirated with no flow straightener in front of it, turbulent flow and distortion of the size distributions can be expected. Anisokinetic sampling and errors in the sampling volume can explain the concentration overestimation. For the other instruments, the biases were constant during the campaign and independent of the wind speed and the droplet size (not shown). They are attributed to the assessment of the sampling volume. This includes errors in the sampling speed, the laser width and the DOF. The listed uncertainties are very difficult to quantify and they can reach rather high values. Thus, it seems to be a more productive approach to correct the measured data without computation of all the errors related to the sampling volume. The approach is discussed in the following section.

\subsection{Improvement of data processing}

The instrument concentration biases observed in Sect. 3.2 lead to the need to standardize the recorded data. The most natural way is to standardize the measurements with instruments which are not based on single particle counting but on the measurements of an ensemble of particles (i.e., from an integrated value). Such measurements are performed by the PVM-100 and the PWD.

Since good agreement was found between the extinction coefficients measured by the PVM and the PWD (Fig. 6), these two instruments can be used as absolute reference of the extinction of cloud particles. As the PWD was the only instrument working during the entire campaign, all recorded data are standardized according to this instrument. Hence, the data of other instruments were averaged over $1 \mathrm{~min}$ according to the PWD time resolution.

Figure 9 presents the comparison between 1 min averaged PWD extinctions and the data obtained in the wind tunnel for all the experiments, as a function of the wind tunnel air speed. The results show good correlations $\left(R^{2}>0.7\right)$, and the slope of the regression curves corresponds to the correction coefficient applied to the sampling volume of the probes. The dispersion can be attributed to the spatial difference between the instruments on the roof and in the wind tunnel and the instrumental errors. Ratios of $0.44,0.63$ and 1.04 were found for the SPP, the CDP 2 and the CDP 1, respectively. The correlation coefficient for the CDP 1 is lower than for the other wind tunnel instruments as a result of missing data from the 22 May experiment not being available (see Table 1). Accordingly, the number of points and the range of the extinction values are lower. As those coefficients are linked to the modification of the sampling volume and number calibration, they can be applied to the concentration, the extinction and the LWC with a simple relation of proportionality. Moreover, as discussed in Sect. 3.1, and as shown in Fig. 9, air speed in the wind tunnel has no influence on the measured data when the sampling volume correction is taken into account. This agrees with the results obtained for the 16 May and is shown in Fig. 3. However, the measurements performed with an air speed equal to $10 \mathrm{~m} \mathrm{~s}^{-1}$ were removed from the data set because of the high discrepancies with the PWD observations $\left(R^{2}=0\right.$ for the SPP and 0.4 for the CDP 1$)$, meaning that the sampling is inadequate at this speed. For cloud measurements, it is thus recommended to use the PUY wind tunnel with an air speed higher than $10 \mathrm{~m} \mathrm{~s}^{-1}$.

In a similar way Fig. 10 presents the comparison of the PWD extinctions with the instruments placed on the mast during the campaign, as a function of the external wind speed (right panels). The FM-100 and PWD measurements are correlated, even though the FM-100 extinction is underestimated by a factor of 2 compared to the PWD reference measurements. This factor is of the same order of magnitude as the bias found when comparing the PWD to the instruments positioned in the wind tunnel (Fig. 9). On the other 

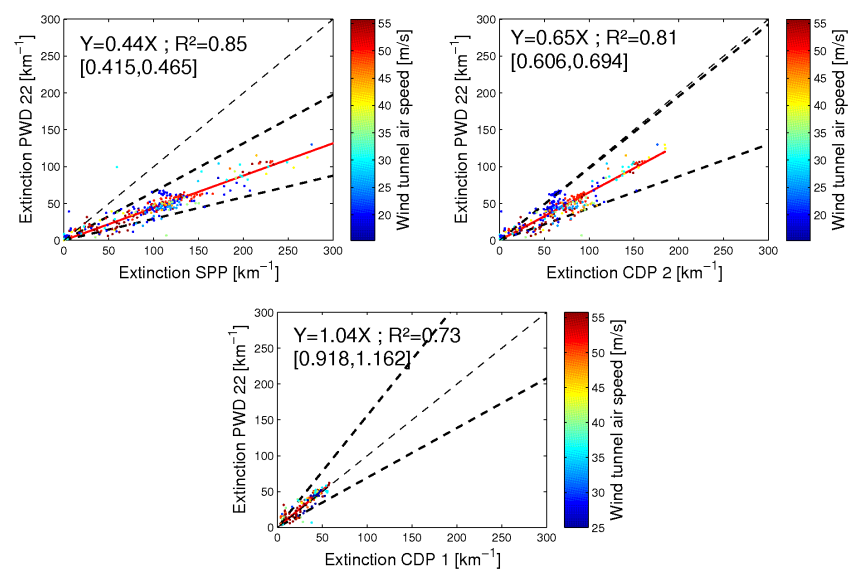

Figure 9. One minute averaged SPP, CDP 2 and CDP 1 extinctions, compared with the PWD extinction for the four wind tunnel experiments. The air speed applied in the wind tunnel is shown on the color bar. The bold dashed lines show the instrumental errors applied to the fit. The confidence intervals with a confidence level of $99 \%$ are given in square brackets.
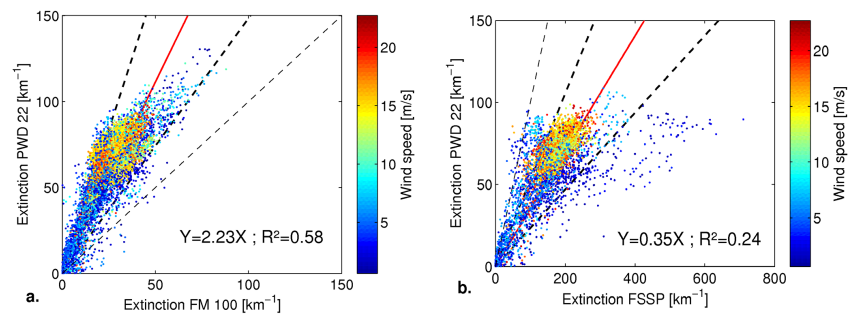

Figure 10. One minute averaged (a) FSSP and (b) FM-100 extinctions vs. the PWD extinction during the entire ROSEA campaign. The measurements have been selected for cloudy events. The red line reveals the linear correlation and the color bar shows the values of the wind speed. The bold dashed lines show the instrumental errors applied to the fit. The $99 \%$ confidence interval of the FM slope value was estimated to be [2.197, 2.263].

hand, Fig. 10 shows only a poor correlation between the FSSP and the PWD extinction coefficient measurements. Additionally, the wind speed seems to have an influence on the FSSP measurements. Several points, corresponding to low wind speeds, show a large overestimation of the extinction measured by the FSSP. Removing the data corresponding to a wind speed lower than $5 \mathrm{~m} \mathrm{~s}^{-1}$, leads to a better correlation $\left(R^{2}=0.55\right)$ and a slope of 0.4 . It should be pointed out that the results remain almost unchanged for the FM-100 when removing the same low wind speed cases. As a consequence, the FSSP seems to be very sensitive to the wind conditions, and this confirms the hypothesis that anisokinetic sampling affects the FSSP measurements, whereas FM-100 inlet system minimizes this effect as much as possible. Indeed, the FM-100 has a transport tube, which allows a more significant aperture angle and ensures a more laminar flow compared to the FSSP. Again, this reveals that low wind speeds contribute heavily towards the amount of scatters so that some physical phenomenon seems to affect the droplet detection (see Sect. 4).

Table 3 presents the summary of the instrumental intercomparison during the ROSEA campaign in terms of the instrumental bias (slope $a$ ) and the correlation coefficient $R^{2}$. In this table, the correlation between two instruments has been computed when the data of the two instruments were available at the same time (see Table 2), with coaxial measurements toward the wind direction, and during stable cloudy periods. One minute averaged data were used to compare the instruments on the roof, while $10 \mathrm{sec}$ averaged data were used to compare instruments when wind tunnel instrumentation is involved. However, due to the time resolution (see Table 1), comparison with the PWD is made at $1 \mathrm{~min}$ average and with the PVM at $5 \mathrm{~min}$ average. The comparisons between the PVM and the wind tunnel instruments are not representative due to the lack of points. Comparisons with the PWD measurements, in bold, give the coefficient to be applied in order to normalize the data of each instrument. All the instruments, except the FSSP, show at least an acceptable correlation $\left(R^{2} \geq 0.6\right)$ with the PWD during the entire campaign, independently of the meteorological conditions.

Appendix A presents experiments devoted to the assessment of the particle speed inside the FSSP inlet as a function of the wind and suction speed. To summarize briefly, the variations of the particle transit speed was found to not directly depend of the suction speed of the pump. Our measurements showed that the ramming effect (Choularton et al., 1986) was not significant. However, it is shown that the inertial concentration effect (Gerber et al., 1999) can be significant. In addition, average transit speed was found to be dependent of the droplets diameter (see Fig. 13a), with a larger dispersion for small particles $(\leq 18 \mu \mathrm{m})$. This confirms the hypothesis of the FSSP anisokinetic sampling with potential turbulent fluxes, leading to a bad correlation with the PWD. A correction which would be proportional to the concentration is thus not possible for the FSSP. Moreover, as the extinction comparisons of the SPCs with the PWD provide correlated linear regression, without saturation, the coincidence phenomenon was assumed negligible.

Up to now we have investigated the coherence of performed measurements using the different probes sampling isoaxially to the main wind stream and showed a way to correct and standardize the data. In the following section, we will investigate the effect of non-isoaxial sampling on the measurements.

\subsection{Effect of wind direction}

In this section we focus on experiments where the mast was oriented in different directions with respect to the main wind stream. Each position was maintained during $5 \mathrm{~min}$ and the orientation was regularly moved back and forth to an isoaxial position to check if the cloud properties remained unchanged 

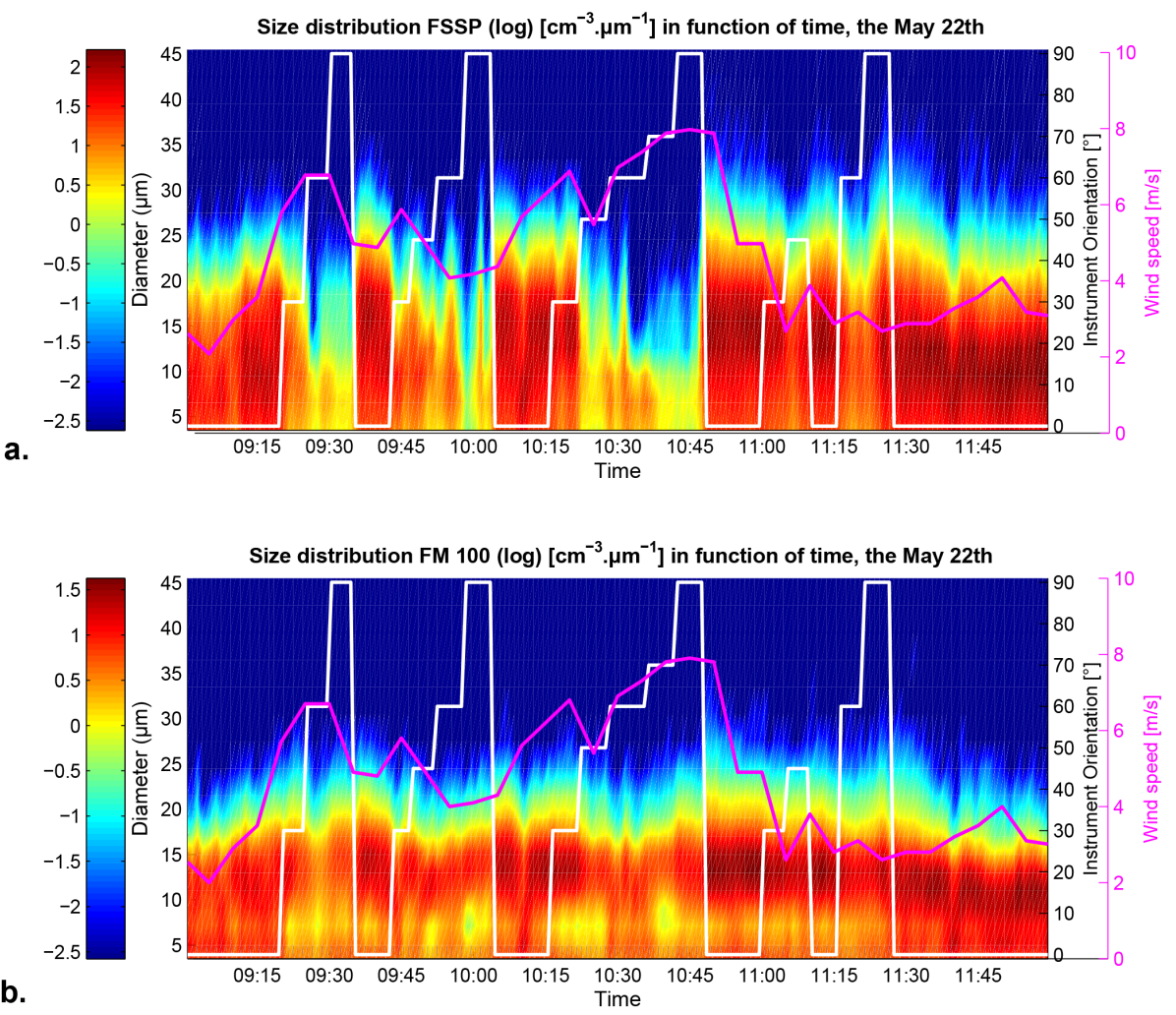

Figure 11. FSSP (a) and FM-100 (b) time series of the size distribution $\left(\mathrm{cm}^{-3} \mu \mathrm{m}^{-1}\right)$ during 22 May. The angle between the wind direction and the mast direction is plotted in white and the wind speed in magenta.

during the experiment. Four measurement series were carried out during 22 May. The wind was blowing west all day long and the cloud properties were rather stable. Despite the sampling anisotropy of the FSSP, the orientation experiments for a given wind speed are reliable.

Figure 11 presents the temporal evolution of the FSSP and FM-100 size distributions along with the wind speed and the deviation angle between the instrument orientation and the wind direction. First, for the measurement with an angle equal to $0^{\circ}$, the cloud size distribution is almost unchanged throughout the experiment. The FSSP LWC and number concentration are approximately $1 \mathrm{~g} \mathrm{~m}^{-3}$ and $1000 \mathrm{~cm}^{-3}$, respectively. Notable changes are observed from angles of $30^{\circ}$. The concentration decreases with increasing angles and with a more pronounced impact for large water droplets $(>15 \mu \mathrm{m}$ approximately). An impact on the small droplets is also seen for large angles, but appears to be lower at low wind speeds. Indeed, comparing the series 3 and 4 with the average values of wind speed of 7 and $3 \mathrm{~m} \mathrm{~s}^{-1}$, the size distribution shows more of a decrease in concentration when the wind is strong. The FM-100 shows the same behavior but with a lower sensitivity.

The impact of the combination of both wind speed and direction on the probe's efficiency to sample cloud droplets is clearly illustrated in Fig. 12, which shows the cloud droplet
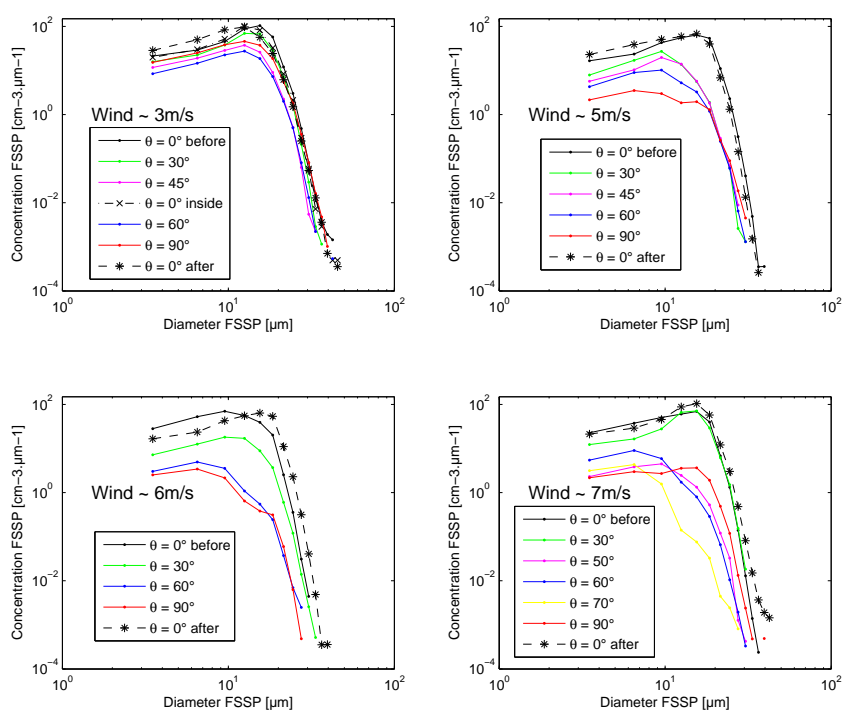

Figure 12. FSSP size distribution averaged for each angle $\theta$ corresponding to the angle between the wind direction and the instrument orientation, for the four manipulations. The averaged wind speed is indicated for each experiment. 
Table 3. Summary of the cloud extinction coefficient intercomparison performed during ROSEA. The coefficient $a$ is the slope of the linear regression; the correlation coefficient $R^{2}$ is also indicated. The bold parts correspond to the standardization of each instrument according to the PWD; the values given by the fitting coefficient $a$ correspond to the factor of standardization.

\begin{tabular}{|c|c|c|c|c|c|c|}
\hline & \multicolumn{3}{|c|}{ Roof } & \multicolumn{3}{|c|}{ Wind tunnel } \\
\hline & FM-100 & PVM & FSSP & SPP & CDP2 & CDP1 \\
\hline PWD & $a=2,23 ; R^{2}=0,58$ & $a=1,17 ; R^{2}=0,86$ & $a=0,35 ; R^{2}=0,24$ & $a=0,44 ; R^{2}=0,86$ & $a=0,66 ; R^{2}=0,82$ & $a=1,04 ; R^{2}=0,73$ \\
\hline FM-100 & & $a=0,45 ; R^{2}=0,74$ & $a=0,15 ; R^{2}=0,79$ & $a=0,26 ; R^{2}=0,61$ & $a=0,39 ; R^{2}=0,61$ & $a=0,45: R^{2}=0,66$ \\
\hline PVM & & & $a=0,34 ; R^{2}=0,64$ & - & - & - \\
\hline FSSP & & & & no correlation & no correlation & no correlation \\
\hline SPP & & & & & $a=0,69 ; R^{2}=0,95$ & $a=2,06 ; R^{2}=0,9$ \\
\hline CDP2 & & & & & & $a=1,37 ; R^{2}=0,91$ \\
\hline CDP1 & & & & & & \\
\hline
\end{tabular}

Table 4. FSSP concentration loss in percentage compared to the isoaxial measurement concentration, as a function of the wind speed and the angle between wind direction and instrument orientation. For each angle and wind speed value, this percentage is computed for the entire size range ( 2 to $45 \mu \mathrm{m})$, the small particles ( 2 to $14 \mu \mathrm{m})$ and the large particles (14 to $29 \mu \mathrm{m}$ ).

\begin{tabular}{llrrrr}
\hline & Wind & $3 \mathrm{~m} \mathrm{~s}^{-1}$ & $5 \mathrm{~m} \mathrm{~s}^{-1}$ & $6 \mathrm{~m} \mathrm{~s}^{-1}$ & $7 \mathrm{~m} \mathrm{~s}^{-1}$ \\
\hline $30^{\circ}$ & Total & 29 & 74 & 75 & 28 \\
& 2 to $14 \mu \mathrm{m}$ & 31 & 58 & 68 & 30 \\
& 14 to $29 \mu \mathrm{m}$ & 25 & 94 & 86 & 26 \\
\hline $60^{\circ}$ & Total & 71 & 88 & 95 & 93 \\
& 2 to $14 \mu \mathrm{m}$ & 65 & 82 & 93 & 87 \\
& 14 to $29 \mu \mathrm{m}$ & 80 & 96 & 99 & 99 \\
\hline $90^{\circ}$ & Total & 46 & 95 & 96 & 98 \\
& 2 to $14 \mu \mathrm{m}$ & 41 & 93 & 95 & 97 \\
& 14 to $29 \mu \mathrm{m}$ & 55 & 97 & 99 & 100 \\
\hline
\end{tabular}

size distribution, averaged for each angle $\theta$ and average wind speed. The percentage of the FSSP isoaxial number concentration loss for each angle and wind speed values is shown in Table 4. This percentage is computed for the total size range of droplets, for small and for large droplets, arbitrarily defined as a droplet diameter lower or greater than $14 \mu \mathrm{m}$ respectively. On average, the greater the angular deviation from isoaxial configuration is, the more the size distribution is reduced, except for a $3 \mathrm{~m} \mathrm{~s}^{-1}$ wind speed. For wind speed 5,6 and $7 \mathrm{~m} \mathrm{~s}^{-1}$, the total percentages displayed on Table 4 go up from 74,75 and $28 \%$ to 95,96 and $98 \%$, respectively. The results also show that, for the same angle of deviation, the percentage increases with increasing wind speed, with only one exception for $30^{\circ}$ and a wind speed of $7 \mathrm{~m} \mathrm{~s}^{-1}$. Thus, with increasing wind speed, the total percentage goes up from 88 to $93 \%$ for $60^{\circ}$ and from 95 to $98 \%$ for $90^{\circ}$.

However for a wind speed of approximately $3 \mathrm{~m} \mathrm{~s}^{-1}$, the size distribution shows very small changes. Despite a ratio of about 4 between the coaxial and a deviation angle of $60^{\circ}$, the size distribution displays the same shape whatever the angle is. Indeed, the particle loss percentages, presented in
Table 5. Same as Table 4, for the FM-100.

\begin{tabular}{llrrrr}
\hline Wind & $3 \mathrm{~m} \mathrm{~s}^{-1}$ & $5 \mathrm{~m} \mathrm{~s}^{-1}$ & $6 \mathrm{~m} \mathrm{~s}^{-1}$ & $7 \mathrm{~m} \mathrm{~s}^{-1}$ \\
\hline $30^{\circ}$ & Total & 15 & 43 & 34 & 21 \\
& 2 to $14 \mu \mathrm{m}$ & 16 & 32 & 34 & 21 \\
& 14 to $29 \mu \mathrm{m}$ & 18 & 74 & 35 & 31 \\
\hline $60^{\circ}$ & Total & 45 & 55 & 68 & 62 \\
& 2 to $14 \mu \mathrm{m}$ & 41 & 44 & 67 & 50 \\
& 14 to $29 \mu \mathrm{m}$ & 62 & 84 & 71 & 90 \\
\hline $90^{\circ}$ & Total & 37 & 58 & 47 & 54 \\
& 2 to $14 \mu \mathrm{m}$ & 33 & 59 & 52 & 52 \\
& 14 to $29 \mu \mathrm{m}$ & 49 & 67 & 16 & 52 \\
\hline
\end{tabular}

Table 4 for small and the large droplets, show very small differences compared to the other wind speed values. The size distribution could then be corrected by applying a constant factor. However, for wind speeds higher than $5 \mathrm{~m} \mathrm{~s}^{-1}$, the FSSP size distribution shape changes and the effective diameter decreases if the instrument is not facing the wind. Table 4 shows that the particle loss percentage for small particles is almost always lower than for larger droplets. This means that the reduction of the measured particle number concentrations resulting from changes in instrument orientation is more efficient for large particles. An inadequate orientation of the mast leads to an underestimation of the effective diameter. Therefore, a simple correction of the size distribution is not possible if the wind is greater than $3 \mathrm{~m} \mathrm{~s}^{-1}$ and the deviation angle is larger than $30^{\circ}$.

Table 5 shows the results for the FM-100. For the same wind speed and direction, the values of the FM-100 concentration loss are systematically lower than for the FSSP. This means that the FM-100 undergoes a weaker loss of measured particles when the instruments are not facing the wind. The variations of the FM-100 concentration loss with the wind speed and the angle are less obvious than variations of the FSSP. Moreover, the amplitude of these variations is much weaker than for the FSSP, with a minimum of $15 \%$ and a maximum of $68 \%$. This confirms that the FM-100 is less 

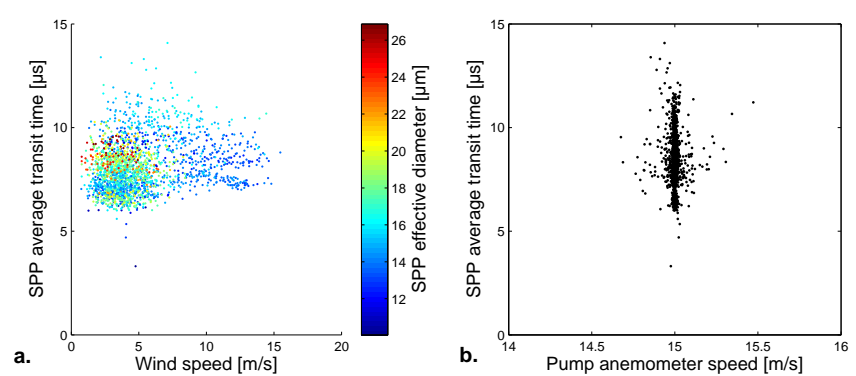

Figure 13. SPP average transit time as a function of the ambient wind speed (a) and of the pump suction speed (b). The colors show the effective diameter measured by the SPP. The data are averaged over $1 \mathrm{~min}$.

sensitive to the wind speed and orientation than the FSSP100. The experimental data presented in Table 5 corroborate with the modeling results by Spiegel et al. (2012) who investigated the particle losses caused by increasing sampling angle for the wind-velocity range from 0.5 to $6.2 \mathrm{~m} \mathrm{~s}^{-1}$ and the sampling speed of $5.25 \mathrm{~m} \mathrm{~s}^{-1}$. Our study shows that the FM particle losses decrease with increasing wind speed for sampling angles lower than $30^{\circ}$ and increase for sampling angles higher than $30^{\circ}$. In addition, for any wind speed greater than $3 \mathrm{~m} \mathrm{~s}^{-1}$, the particle losses increase with particle diameter and sampling angle.

\section{Conclusions}

Accurate measurements of cloud microphysical properties are crucial for a better understanding of cloud processes and their impact on the climate. A large number of cloud instruments have been developed since the late 1970s. However, accurate comparisons between instruments are still scarce, in particular comparisons between ground-based and airborne sampling conditions. To address this problem, we performed intercomparisons of both ground-based and wind tunnel measurements performed with various instrumentations during the ROSEA campaign at the station of the Puyde-Dôme (central France, 1465 m a.s.1.) in May 2013. This instrumental intercomparison includes a FSSP, a Fog Monitor 100, a PWD and a PVM-100, used during ground-based conditions, and two CDPs and a SPP-100 used in the wind tunnel.

Our results show very good correlations between the measurements performed by the different instruments, especially, for the shape of the size distribution and the effective diameter values. Absolute effective diameter values show good agreement within the $10 \%$ average instrument uncertainty, however total concentration values can diverge up to a factor of 5. This result can be explained by the errors in the sampling volume and speed. Comparisons between groundbased and controlled wind measurements show good correlations. However the concentration values biases still re-

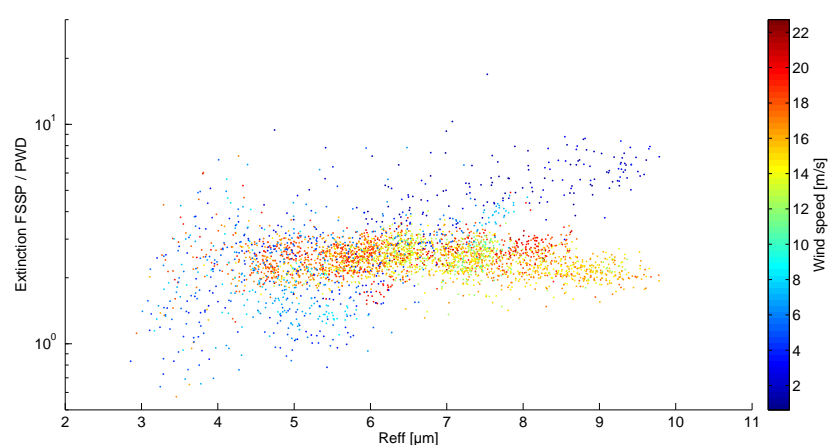

Figure 14. Extinction ratio between the FSSP and the PWD as a function of effective radius of cloud droplets and ambient wind speed during the ROSEA campaign.

main. As all the uncertainties are often difficult to assess, we thus propose to standardize data with a PWD. This is a reliable instrument, which does not use a sample volume. The data were normalized based on the bulk extinction coefficient measurements performed by the PWD. Except for the FSSP, the results show that the measurements do not depend significantly on the air speed (wind speed or wind tunnel suction speed) or droplet size. Moreover, the measurements can be standardized with a simple relation of proportionality, with a coefficient comprised between 0.43 and 2.2 , which is valid for the entire campaign. This is not applicable to the groundbased FSSP measurements which showed anisokinetic sampling and a high sensitivity to the wind speed and direction. Indeed, data from these measurements are highly variable when the wind speed was lower than the theoretical air speed through the inlet. The overestimation of extinction measured by the FSSP, compared to the PWD, showed agreements with the Gerber et al. (1999) study, which highlights the inertial concentration effects.

Moreover, as the FSSP and the FM were installed on a mast, which can be oriented manually; this system allowed us to highlight the effect of an increasing angle between instrument orientation and wind direction on the FSSP and Fog Monitor data. The mast orientation was modified with an angle ranging from 30 to $90^{\circ}$ angle with wind speeds from 3 to $7 \mathrm{~m} \mathrm{~s}^{-1}$. The results show that the induced number concentration loss is between 29 and $98 \%$ for the FSSP and between 15 and $68 \%$ for the FM-100. This study revealed that it is necessary to be very critical with cloud measurements when the wind speed is lower than $3 \mathrm{~m} \mathrm{~s}^{-1}$ and when the angle between the wind direction and the orientation of the instruments is greater than $30^{\circ}$.

Finally the high dispersion of the ground-based FSSP measurements compared to the other instruments is explained as follows. The transit speed of droplets in the FSSP sampling volume was investigated using the SPP measurements on the mast. The ground-based SPP observations showed a strong variability in the transit speed of the cloud 
droplets. This variability did not depend on the variations of the pump aspiration or the wind speed. As this effect was more pronounced for small particles, the concentration effect of the mean flow and the presence of turbulent flow inside the FSSP inlet could be a plausible explanation of the discrepancies of the measurements based on particle counting. 


\section{Appendix A: Ramming and inertial concentration effect}

In order to investigate the influence of the wind speed on the FSSP response, three additional experiments were performed with the SPP-100 installed on the mast along with the FSSP (from 13 to 15 November 2013).

The SPP has an internal estimation of the droplet speed within the sampling volume: the so-called transit speed. We maintain that ideally the transit speed through the laser beam should be the same as the SPP sampling speed. In addition, this also allows us to estimate the values and the variations of the sampling volume, needed in the computation of the concentration, when assuming that the air speed is close to the particle speed. The SPP was installed in the position of the FSSP. Its theoretical sampling speed in the instrument's inlet is $9 \mathrm{~m} \mathrm{~s}^{-1}$. The instruments on the mast were always oriented to assure coaxial measurements. The goal of this study was to use the SPP transit speed measurements to quantify the FSSP sampling volume as a function of the wind speed and the pump aspiration speed, in order to have a better understanding of the sampling processes in the inlets.

Over the period of 13-15 November, the wind speeds ranged from 0 to $15 \mathrm{~m} \mathrm{~s}^{-1}$ and LWC values varied between 0 and $1 \mathrm{~g} \mathrm{~m}^{-3}$. The SPP transit time showed relatively high variations between 7 and $12 \mu$ s. Transit time is theoretically inversely proportional to transit speed. These values correspond to SPP transit speeds between 15 and $25 \mathrm{~m} \mathrm{~s}^{-1}$, which are higher than the theoretical value of $9 \mathrm{~m} \mathrm{~s}^{-1}$ that was taken into account for the data processing of both the SPP and the FSSP. Even if the transit speed depends on the particle size distribution, these differences could explain the overestimation of the concentration and the LWC obtained from the FSSP data. It emphasizes the need for an accurate estimation of the sampling volume. Indeed, an error in the determination of the DOF or the air speed, combined with the absence of the number calibration coefficient, leads to potentially high biases even if the instruments are still capable of capturing the variations in cloud properties.

In order to explain the variations of the SPP transit time, it can be compared to the wind speed and the pumping speed. Figure 13 presents the comparisons of 1 min averaged data. In the Fig. 13a, the effective diameter measured by the SPP is also shown on the color bar. We observe that the SPP transit time is not dependent on the wind speed. It should be pointed out that the effective diameter values higher than $20 \mu \mathrm{m}$ were observed only during a relatively small period of time when the wind speed was below $7 \mathrm{~m} \mathrm{~s}^{-1}$. The results of Fig. 13a show that droplets smaller than $20 \mu \mathrm{m}$ have a transit time between 6 and $14 \mu \mathrm{s}$, whereas the range is between 7 and $10 \mu \mathrm{s}$ for droplets larger than $20 \mu \mathrm{m}$. Small particles tend to be driven by streamlines and thus show more dispersion in SPP transit time than larger particles. This highlights anisotropy in the sampling suction, which is potentially turbulent. In the non-isokinetic conditions and for a high Reynolds number (about $2 \times 10^{4}$ ), turbulent flows are expected inside and near the FSSP inlet. From Fig. 13b, we observe that the pump anemometer speed is very stable. That cannot explain the SPP transit speed variations. Thus, the SPP transit speed fluctuates independently of the wind speed or of the pump aspiration. As a consequence, there is no simple explanation to describe the absolute values and the variations of the SPP transit time.

Choularton et al. (1986) compared the FSSP volume sampling rate $V$ to wind speed values. In that experiment, the ground-based FSSP was coupled with a fan with a sampling speed of $26 \mathrm{~m} \mathrm{~s}^{-1}$, which corresponds to a value of $V=8.14 \mathrm{~cm}^{3} \mathrm{~s}^{-1}$ in windless air conditions. The wind speed varied approximately between 10 and $20 \mathrm{~m} \mathrm{~s}^{-1}$. The measured FSSP volume sampling rate $V$ increased from 12 to $16 \mathrm{~cm}^{3} \mathrm{~s}^{-1}$ with increasing wind speed. Such values correspond to the sampling speed from 38 to $51 \mathrm{~m} \mathrm{~s}^{-1}$. Choularton et al. (1986) concluded that the ventilation speed and hence the volume sampling rate is modified by the forcing of air through the sample tube by the wind, known as the ramming effect.

This ramming effect was not observed during our November 2013 experiments. First, the sampling air speed within the FSSP inlet was higher than expected ( $\geq 15$ instead of $9 \mathrm{~m} \mathrm{~s}^{-1}$ ). This difference can be attributed to the underestimation of the diameter value of the instrument's laser beam (that value was set at manufacture). The results of Fig. 13 show that the ramming effect cannot explain the overestimation of the concentration of the FSSP and SPP or the relatively high variability of the SPP transit time. At the same time, the variability observed in the SPP transit time measurements explains the variations in number concentrations when compared to the PWD (Figs. 9 and 10). In addition, the sampling speed problem revealed by the SPP transit speed could explain why the FSSP number concentration and extinction show high discrepancies with the SPP and the CDP 1 (both installed in the wind tunnel) and the PWD (mounted on the roof terrace) measurements.

Gerber et al. (1999) compared the LWC measurements of the FSSP and the PVM-100 during ground-based experiments. This study highlights the need of accurate ambient wind speed measurements and information on instrument orientation with respect to the wind direction. In addition, this study suggests that the FSSP overestimates the concentration due to the droplet trajectories inside the flow accelerator when the ambient air speed is inferior to the velocity near the position of the laser. A simple trajectory model was used to understand if the suction used to draw droplets into the sampling tube of the FSSP can cause changes in the droplet concentration at the point where the laser beam interacts with the droplets. The modeling was performed for a sampling velocity of $25 \mathrm{~m} \mathrm{~s}^{-1}$ and two wind-speed values of 0 and $2 \mathrm{~m} \mathrm{~s}^{-1}$. As expected, the air flow converges and accelerates into the inlet. At the same time, droplets are unable to follow the curved streamlines and, due to the droplets' inertia, show a tendency to accumulate near the centerline of the 
insert where the sampling volume is located. The overestimation can be determined by the enhancement factor $F$ given by the ratio of FSSP concentration near the centerline of the insert to the ambient concentration. The enhancement factor decreases with increasing wind speed (from 0 to $2 \mathrm{~m} \mathrm{~s}^{-1}$ ) and increases with increasing droplet effective radius (from 0 to $25 \mu \mathrm{m}$ ). For a droplet radius of $25 \mu \mathrm{m}$, the concentration enhancement varies between a factor of 3.5 and 30 depending on the ambient air velocity. For droplets smaller than $R_{\text {eff }}=5 \mu \mathrm{m}$ the enhancement is less than $10 \%$. Errors are small for droplet radius less than $5 \mu \mathrm{m}$ but increase rapidly with increasing droplet size (Gerber et al., 1999).

To compare our results with Gerber et al. (1999), Fig. 14 displays the ratio between the FSSP and PWD extinctions as a function of the effective radius provided by the FSSP and the wind speed, for the entire ROSEA campaign. The lowest values of the PWD extinction were removed in order to avoid unrealistic ratio values. The ratio of extinction or LWC (used in Gerber et al., 1999) is the same within the hypothesis that it is due to an inaccurate assessment of the sampling volume. As we selected the PWD as the reference instrument, this ratio is similar to the enhancement factor $F$ from Gerber et al. (1999). Our results show high values and variability of the ratio for low values of the wind speed, whereas the ratio is constant $(\sim 2.5$ which correspond to the slope of 0.4 seen in the Fig. 10) when the wind speed is greater than $5-6 \mathrm{~m} \mathrm{~s}^{-1}$. However, it seems that there is some increase in the ratio for diameter values greater than $6 \mu \mathrm{m}$, which is in agreement with the conclusion of Gerber et al. (1999). For diameters lower than $6 \mu \mathrm{m}$, an important dispersion of points is observed that should confirm the idea that potential turbulent flow in the inlet can sweep the smallest particles and so can alter the measurements.
Thus, a relatively good agreement is observed between the inertial concentration effect shown by Gerber et al. (1999) and our results. As a consequence, we have indications which tend to show that the FSSP measurements with a wind speed that is too low have to be removed if the variations do not correlate with data of other instruments. 
Acknowledgements. This work was performed within the framework ROSEA (Réseau d'Observatoires pour la Surveillance et l'Exploration de l'Atmosphère) and ACTRIS (Aerosols, Clouds and Trace gases Research Infra Structure Network). It was also supported by the French ANR CLIMSLIP. The authors are grateful to the OPGC (Observatoire de Physique du Globe de Clermont) for monitoring at the PdD station and Evelyn J. Freney, D. Baumgardner, C. Towhy and H. Gerber for their help in improving the manuscript. G. Guyot is grateful to Conseil Général de l'Allier for the financial support of his work.

Edited by: P. Herckes

\section{References}

Albrecht, B. A.: Aerosols, cloud microphysics, and fractional cloudiness, Science, 245, 1227-1230, 1989.

Asmi, E., Freney, E., Hervo, M., Picard, D., Rose, C., Colomb, A., and Sellegri, K.: Aerosol cloud activation in summer and winter at puy-de-Dôme high altitude site in France, Atmos. Chem. Phys., 12, 11589-11607, doi:10.5194/acp-12-11589-2012, 2012.

Bain, M. and Gayet, J. F.: Contribution to the modeling of the ice accretion process: ice density variation with the impacted surface angle, Ann. Glaciol., 4, 19-23, 1983.

Baumgardner, D.: An analysis and comparison of five water droplet measuring instruments, J. Appl. Meteor, 22, 891-910, 1983.

Baumgardner D., Strapp W., Dye J. E.: Evaluation of the Forward Spectrometer Probe. Part II: Corrections for coincidence and dead time losses, J. Atmos. Oceanic Technol., 2, 626-632, 1985.

Baumgardner D. and Spowart M.: Evaluation of Forward Spectrometer Probe. Part III: Time response and laser Inhomogeneity limitations, J. Atmos. Oceanic Technol., 7, 666-672, 1990.

Baumgardner, D., Brenguier, J., Bucholtz, A., Coe, H., DeMott, P., Garrett, T., Gayet, J., Hermann, M., Heymsfield, A., Korolev, A., Krämer, M., Petzold, A., Strapp, W., Pilewskie, P., Taylor, J., Twohy, C., Wendisch, M., Bachalo,W., and Chuang, P.: Airborne instruments to measure atmospheric aerosol particles, clouds and radiation: A cook's tour of mature and emerging technology, Atmos. Res., 102, 10-29, doi:10.1016/j.atmosres.2011.06.021, 2011.

Bennartz, R., Shupe, M. D., Turner, D., Walden, V. P., Steffen, K., Cox, C. J., Kulie, M. S., Miller, N. B., and Pettersen, C.: July 2012 Greenland melt extent enhanced by low-level liquid clouds, Nature, 496, 83-86, doi:10.1038/nature12002, 2013.

Boucher, O., Randall, D., Artaxo, P., Bretherton, C., Feingold, G., Forster, P., Kerminen, V.-M., Kondo, Y., Liao, H., Lohmann, U., Rasch, P., Satheesh, S. K., Sherwood, S., Stevens B., and Zhang, X. Y.: Clouds and Aerosols, in: Climate Change 2013: The Physical Science Basis. Contribution of Working Group I to the Fifth Assessment Report of the Intergovernmental Panel on Climate Change, Cambridge University Press, Cambridge, United Kingdom and New York, NY, USA, 88 pp., 2013.

Boulon, J., Sellegri, K., Hervo, M., Picard, D., Pichon, J.-M., Fréville, P., and Laj, P.: Investigation of nucleation events vertical extent: a long term study at two different altitude sites, Atmos. Chem. Phys., 11, 5625-5639, doi:10.5194/acp-11-56252011, 2011.
Bourcier, L., Sellegri, K., Chausse, P., Pichon, J. M., and Laj, P.: Seasonal variation of water-soluble inorganic components in aerosol size-segregated at the puy de Dôme station (1,465 m a.s.1.), France, J. Atmos. Chem., 69, 47-66, doi:10.1007/s10874-012-9229-2, 2012.

Brenguier, J. L., Bourrianne, T., de A. Coelho, A., Isbert, J., Peytavi, R., Trevarin, D., and Weschler, P.: Improvements of Droplet Size Distribution Measurements with the Fast-FSSP (Forward Scattering Spectrometer Probe), J. Atmos. Oceanic Technol., 15, 1077-1090, 1998.

Brenguier, J. L., Pawlowska, H., and Schüller, L.: Cloud microphysical and radiative properties for parameterization and satellite monitoring of the indirect effect of aerosol on climate, J. Geophys. Res., 108, 8632, doi:10.1029/2002JD002682, 2003.

Brenguier, J.-L., Burnet, F., and Geoffroy, O.: Cloud optical thickness and liquid water path - does the $k$ coefficient vary with droplet concentration?, Atmos. Chem. Phys., 11, 9771-9786, doi:10.5194/acp-11-9771-2011, 2011.

Brenguier, J.-L., Bachalo, W. D., Chuang, P. Y., Esposito, B. M., Fugal, J., Garrett, T., Gayet, J.-F., Gerber, H., Heymsfield, A., Kokhanovsky, A., Korolev, A., Lawson, R. P., Rogers, D. C., Shaw, R. A., Strapp, W., and Wendisch, M.: In Situ Measurements of Cloud and Precipitation Particles, in Airborne Measurements for Environmental Research, in: Methods and Instruments, edited by: Wendisch, M. and Brenguier, J.-L., WileyVCH Verlag GmbH \& Co. KGaA, Weinheim, Germany, 225301, doi:10.1002/9783527653218.ch5, 2013.

Burnet F. and Brenguier, J. L.: Validation of droplet spectra and liquid water content measurements, Phys. Chem. Earth, 24, 249254, 1999.

Burnet F. and Brenguier, J. L.: Comparison between standard and modified Forward Scattering Spectrometer Probes during the Small Cumulus Microphysics Study, J. Atmos. Oceanic Technol., 19, 1516-1531, 2002.

Cerni, T.: Determination of the size and concentration of cloud drops with an FSSP, J. Climate Appl. Meteor., 22, 1346-1355, 1983.

Choularton, T.W., Consterdine, I.E., Gardiner, B.A., Gay, M.J., Hill, M.K., Latham, J., Stromberg, M.: Field studies of the optical and microphysical characteristics of clouds enveloping Great Dun Fell, Q. J. Roy. Meteor. Soc., 112, 131-148, 1986.

Deguillaume, L., Charbouillot, T., Joly, M., Vaïtilingom, M., Parazols, M., Marinoni, A., Amato, P., Delort, A.-M., Vinatier, V., Flossmann, A., Chaumerliac, N., Pichon, J. M., Houdier, S., Laj, P., Sellegri, K., Colomb, A., Brigante, M., and Mailhot, G.: Classification of clouds sampled at the puy de Dôme (France) based on $10 \mathrm{yr}$ of monitoring of their physicochemical properties, Atmos. Chem. Phys., 14, 1485-1506, doi:10.5194/acp-14-14852014, 2014.

Droplet Measurement Technologies: Fog Monitor Model FM-100 Operator Manual (DOC-0088 Revision H), published by Droplet Measurement Technologies, Inc., Boulder, USA, 63 pp., 2011.

Dye, J. E. and Baumgardner D.: Evaluation of the Forward Scattering Spectrometer Probe. Part I: Electronic and Optical Studies, J. Atmos. Oceanic Technol., 1, 329-344, 1984.

Eugster, W., Burkard, R., Holwerda, F., Scatena, F., and Bruijnzeel, L.: Characteristics of fog and fogwater fluxes in a Puerto Rican elfin cloud forest, Agr. Forest. Meteorol., 139, 288-306, doi:10.1016/j.agrformet.2006.07.008, 2006. 
Febvre, G., Gayet, J.-F., Shcherbakov, V., Gourbeyre, C., and Jourdan, O.: Some effects of ice crystals on the FSSP measurements in mixed phase clouds, Atmos. Chem. Phys., 12, 8963-8977, doi:10.5194/acp-12-8963-2012, 2012.

Freney, E. J., Sellegri, K., Canonaco, F., Boulon, J., Hervo, M., Weigel, R., Pichon, J. M., Colomb, A., Prévôt, A. S. H., and Laj, P.: Seasonal variations in aerosol particle composition at the puy-de-Dôme research station in France, Atmos. Chem. Phys., 11, 13047-13059, doi:10.5194/acp-11-13047-2011, 2011.

Gayet, J. F., Febvre G., and Larsen, H.: The reliability of the PMS FSSP in the presence of small ice crystals, J. Atmos. Oceanic Technol., 13, 1300-1310, 1996.

Gayet, J.-F., Mioche, G., Dörnbrack, A., Ehrlich, A., Lampert, A., and Wendisch, M.: Microphysical and optical properties of Arctic mixed-phase clouds. The 9 April 2007 case study., Atmos. Chem. Phys., 9, 6581-6595, doi:10.5194/acp-9-6581-2009, 2009.

Gerber, H.: Liquid water content of fogs and hazes from visible light scattering, J. Climate Appl. Meteor., 23, 1247-1252, 1984.

Gerber, H.: Direct measurement of suspended particulate volume concentration and far-infrared extinction coefficient with a laser diffraction instrument, Appl. Optics, 30, 4824-4831, 1991.

Gerber, H., Arends, B. G., and Ackerman A. S.: New microphysics sensor for aircraft use, Atmos. Res., 31, 235-252, 1994.

Gerber, H., Frick, G., and Rodi, A. R.: Ground-based FSSP and PVM Measurements of Liquid Water Content, J. Atmos. Oceanic Technol., 16, 1143-1149, 1999.

Hangal, S. and Willeke, K.: Aspiration efficiency: unified model for all forward sampling angles, Environ. Sci. Technol., 24, 688691, doi:10.1021/es00075a012, 1990a.

Hangal, S. and Willeke, K.: Overall efficiency of tubular inlets sampling at 0-90 degrees from horizontal aerosol flows, Atmos. Environ., 24, 2379-2386, doi:10.1016/0960-1686(90)90330P, 1990b.

Hervo, M., Sellegri, K., Pichon, J. M., Roger, J. C., and Laj, P.: Long term measurements of optical properties and their hygroscopic enhancement, Atmos. Chem. Phys. Discuss., 14, 27731-27767, doi:10.5194/acpd-14-27731-2014, 2014.

Holmgren, H., Sellegri, K., Hervo, M., Rose, C., Freney, E., Villani, P., and Laj, P.: Hygroscopic properties and mixing state of aerosol measured at the high-altitude site Puy de Dôme (1465 m a.s.1.), France, Atmos. Chem. Phys., 14, 9537-9554, doi:10.5194/acp-14-9537-2014, 2014.

Hoyle, C. R., Webster, C. S., Rieder, H. E., Hammer, E., Gysel, M., Bukowiecki, N., Weingartner, E., Steinbacher, M., and Baltensperger, U.: Chemical and physical influences on aerosol activation in liquid clouds: an empirical study based on observations from the Jungfraujoch, Switzerland, Atmos. Chem. Phys. Discuss., 15, 15469-15510, doi:10.5194/acpd-15-15469-2015, 2015.

Irvine, T. B., Kevdzija, S. L., Sheldon, D. W., and Spera, David A.: Overview of the Icing and Flow Quality Improvements Program for the NASA Glenn Icing Research Tunnel, AIAA-2001-0229, January 2001.

Kamphus, M., Ettner-Mahl, M., Klimach, T., Drewnick, F., Keller, L., Cziczo, D. J., Mertes, S., Borrmann, S., and Curtius, J.: Chemical composition of ambient aerosol, ice residues and cloud droplet residues in mixed-phase clouds: single particle analysis during the Cloud and Aerosol Characterization Ex- periment (CLACE 6), Atmos. Chem. Phys., 10, 8077-8095, doi:10.5194/acp-10-8077-2010, 2010.

Kenneth, V. and Ochs, H.: Warm-rain initiation: An overwiew of Microphysical Mechanisms, J. Appl. Meteorol., 32, 608-625, 1993.

Knollenberg, R. G.: Techniques for probing cloud microstructure, in: Clouds, their formation, optical properties and effects, edited by: Hobbs, P. V. and Deepak, A., Academic Press, New York, USA, 15-92, 1981.

Lance, S., Brock, C. A., Rogers, D., and Gordon, J. A.: Water droplet calibration of the Cloud Droplet Probe (CDP) and inflight performance in liquid, ice and mixed-phase clouds during ARCPAC, Atmos. Meas. Tech., 3, 1683-1706, doi:10.5194/amt3-1683-2010, 2010.

Marinoni, A., Laj, P., Sellegri, K., and Mailhot, G.: Cloud chemistry at the Puy de Dôme: variability and relationships with environmental factors, Atmos. Chem. Phys., 4, 715-728, doi:10.5194/acp-4-715-2004, 2004.

McFarquhar, G., Ghan, S. J., Verlinde, J., Korolev, A., Strapp, J. W., Schmid, B., Tomlinson, J., Wolde, M., Brooks, S., Cziczo, D., Dubey, M., Fan, J., Flynn, C., Gultepe, I., Hubbe, J., Gilles, M., Laskin, A., Lawson, P., Leaitch, W., Liu, P., Liu, X., Lubin, D., Mazzoleni, C., Mac Donald, A.M., Moffet, R., Morrison, H., Ovchinnikov, M., Shupe, D., Turner, D., Xie, S., Zelenyuk, A., Bae, K., Freer, M., and Glen A.: Indirect and Semi-Direct Aerosol Campaign: The Impact of Arctic Aerosols on Clouds, B. Am. Meteorol. Soc., 92, 183-201, doi:10.1175/2010BAMS2935.1, 2011.

Mertes, S., Schwarzenböck, A., Laj, P., Wobrock, W., Pichon, J. M., Orsi, G., and Heintzenberg, J.: Changes of cloud microphysical properties during the transition from supercooled to mixed-phase conditions during CIME, Atmos. Res., 58, 267-294, 2001.

Mie, G.: Beiträge zur Optik trüber Medien, speziell kolloidaler Metallösungen, Ann. Phys.-Berlin, 330, 377-445, 1908.

Petters, J. L., Harrington, J. Y., and Clothiaux, E.: Radiativedynamical feedbacks in low liquid water path stratiform clouds, J. Atmos. Sci., 69, 1498-1512, doi:10.1175/JAS-D-11-0169.1, 2012.

Pinnick, R. G., Garvey, D. M., and Duncan, L. D.: Calibration of Knollenberg FSSP light-scattering counters for measurement of cloud droplets, J. Appl. Meteor., 20, 1049-1057, 1981.

Pruppacher, H. R. and Klett, J. D.: Microphysics of Clouds and Precipitation, Kluwer Academic Publishers, Dordrecht, the Netherlands, 954 pp., 1997.

Randall, D. A., Wood, R. A., Bony, 5 S., Coleman, R., Fichefet, T., Fyfe, J., Kattsov, V., Pitman, A., Shukla, J., Srinivasan, J., Stouffer, R. J., Sumi, A., and Taylor, K. E.: Climate models and their evaluation, in: Climate Change 2007: The Physical Science Basis, edited by: Solomon, S., Qin, D.,Manning, M., Chen, Z., Marquis, M., Averyt, K. B., Tignor, M. and Miller, H. L., Cambridge University Press, Cambridge, UK, 589-662, 2007.

Rogers, D., Stith, J., Jensen, J., Cooper, W., Nagel, D., Maixner, U., and Goyea, O.: Splash artifacts in FSSP measurements; observations and flow modeling studies, 12th conference of cloud physics, Madison, USA, 10-14 July 2006, P2.30, 2006.

Rose, C., Boulon, J., Hervo, M., Holmgren, H., Asmi, E., Ramonet, M., Laj, P., and Sellegri, K.: Long-term observations of cluster ion concentration, sources and sinks in clear sky conditions at 
the high-altitude site of the Puy de Dôme, France, Atmos. Chem. Phys., 13, 11573-11594, doi:10.5194/acp-13-11573-2013, 2013.

Spiegel, J. K., Zieger, P., Bukowiecki, N., Hammer, E., Weingartner, E., and Eugster, W.: Evaluating the capabilities and uncertainties of droplet measurements for the fog droplet spectrometer (FM-100), Atmos. Meas. Tech., 5, 2237-2260, doi:10.5194/amt5-2237-2012, 2012.

Twomey, S.: Pollution and the planetary albedo, Atmos. Environ., 8, 1251-1256, 1974.

Twomey, S.: The influence of pollution on the shortwave albedo of clouds, J. Atmos. Sci., 34, 1149-1152, 1977.

Vaisala: Present Weather Detector PWD22 user's guide, published by Vaisala, Helsinki, Finland, 125 pp., 2004.

Venzac, H., Sellegri, K., Villani, P., Picard, D., and Laj, P.: Seasonal variation of aerosol size distributions in the free troposphere and residual layer at the puy de Dôme station, France, Atmos. Chem. Phys., 9, 1465-1478, doi:10.5194/acp-9-1465-2009, 2009.
Wendisch, M. : A quantitative comparison of ground-based FSSP and PVM measurements, J. Atmos. Oceanic Technol., 15, 887900, 1998.

Wendisch, M., Garrett, T. J., and Strapp, J. W.: Wind tunnel tests of airborne PVM-100A response to large droplets, J. Atmos. Oceanic Technol., 19, 1577-1584, 2002.

Wobrock, W., Flossmann, A., Monier, M., Pichon, J. M., Cortez, L., Fournol, J. F., Schwarzenböck, A., Mertes, S., Heintzenberg, J., Laj, P., Orsi, G., Ricci, L., Fuzzi, S., Brink, H. T., Jongejan, P., and Otjes, R.: The Cloud Ice Mountain Experiment (CIME) 1998: experiment overview and modeling of the microphysical processes during the seeding by isentropic gas expansion, Atmos. Res., 58, 231-265, 2001. 